\title{
How Gradient Affects the Foraging Decisions of Leaf Cutting Ants at the Food Source
}

\author{
Sam Butler
}

A thesis submitted to The University of Gloucestershire in accordance with the requirements of the degree of Master of Science by research in the School of Natural and Social Sciences

September 2019 




\section{Abstract}

The eusocial insects have long held the fascination of scientists for their co-operative behaviour, which can range from a small group of workers, to millions strong colonies, such as those found in the leaf cutting ant, Atta cephalotes. Though decades of research have allowed us some insight into their organisation and methods, there are many things that have gone unexplained.

One of these is the mystery of why Atta consistently takes leaf loads back to the nest that are significantly smaller than would be optimal, when they should in theory optimise leaf transport rate. While compelling evidence has been presented to suggest that it is at least in part to do with how the leaves are processed inside the nest, here I present evidence to suggest that gradient is another key factor. This is a factor which has been explored only very cursorily up until now in leaf cutting ants, with experiments investigating it being extremely limited in scope, suffer from potential methodological errors or deal with grass cutting ants, which share many traits with leaf cutting ants, but have adapted to face different challenges.

Upon a thorough examination of the effects of gradient, it was discovered that $A$. cephalotes favour a cautious, but more reliable method of transport. At almost every point, their behaviour shows the importance of maintaining grip on steep and vertical gradients to the point where it is prioritised over everything else, including speed and load size. While it may seem paradoxical to suggest that smaller loads, carried slower might result in a higher overall rate of leaf collection, a fast, but reckless approach might result in a high proportion of unsuccessful foraging trips, each of which costs energy and time. As a result, by increasing their success, rather than speed, they minimise wasted effort, loss of workers and potentially, have a higher rate of leaf collection over time. This aspect of leaf cutting ant behaviour shows that leaf cutting ants can change their priorities at the feeding site to best maximise transport success at an individual level, which demonstrates previously unappreciated plasticity and a new lens through which to view future investigations into ant foraging behaviour. 
Declaration of own work

I declare that the work in this thesis was carried out in accordance with the regulations of the University of Gloucestershire and is original except where indicated by specific reference in the text. No part of the thesis has been submitted as part of anyother academic award. The thesis has not been presented to any other education institution in the United Kingdom or overseas. Any views expressed in the thesis are those of the author and in no way represent those of the University.

Signed Date 


\section{Acknowledgements}

The following people have been critical to the success of this project and for their contributions, they have most sincere and heartfelt thanks.

Firstly, to Adam Hart, who's expertise, encouragement, assistance in keeping my aims realistic and his unending patience throughout this project.

Second, to Will Carpenter, whose assistance in troubleshooting the method, construction, willingness to cater to every practical need and physical strength made it possible to perform the experiments within.

And lastly, to my mother and my sister, who's unending support, both financial and emotional meant I was able to see this through to completion. 


\section{Contents}

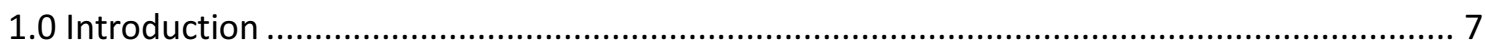

1.1 Contributions of The Fungal Symbiont: Leucoagaricus gongylophorus ............................ 9

1.2 Contributions of The Insect Symbiont: Atta cephalotes ................................................. 10

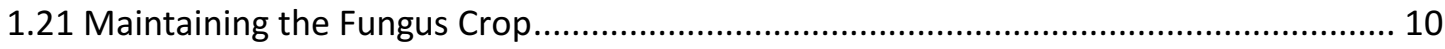

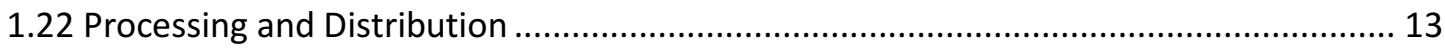

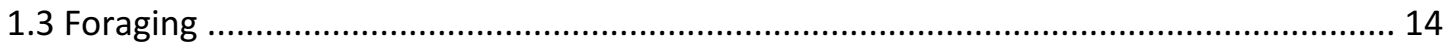

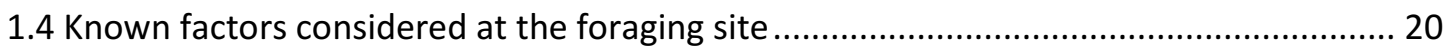

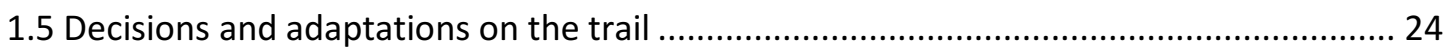

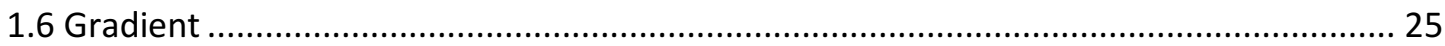

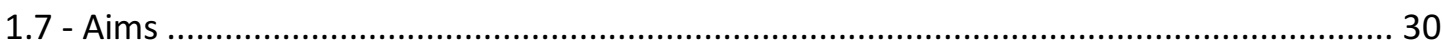

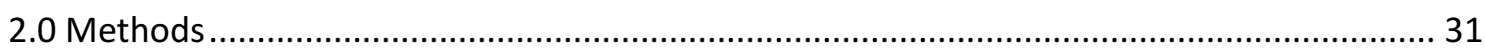

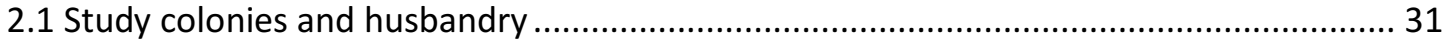

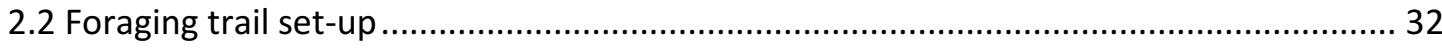

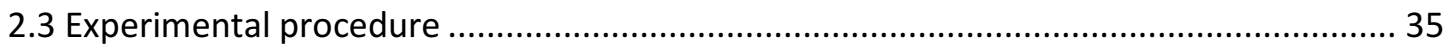

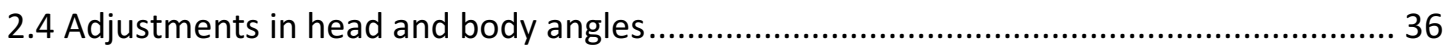

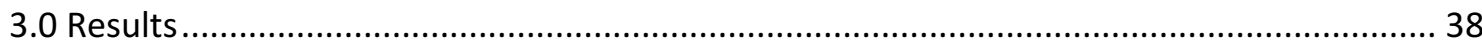

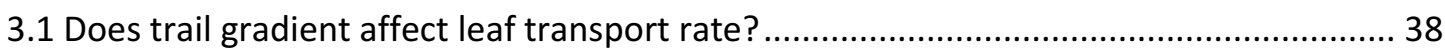

3.2 How do speed, loading ratio and trail gradient interact? ............................................. 39

3.3 Does the trail gradient affect leaf size and leaf mass? ...................................................... 42

3.4 What effect does trail gradient have on how the ants adjust their head and body angles?

3.5 Does gradient affect which ants decide to cut? .............................................................. 46

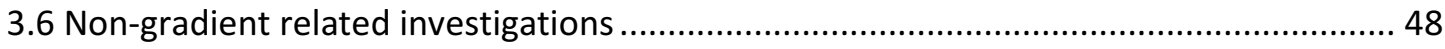

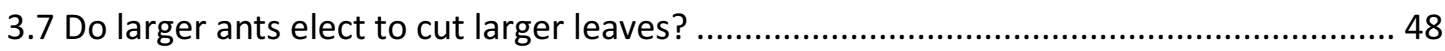

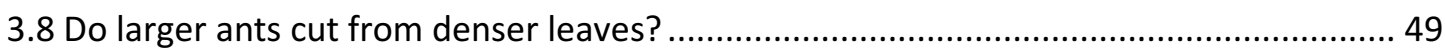

3.9 Do larger ants walk faster, and do they have a faster transport rate?............................. 50

3.10 Do ants carrying larger leaf fragments slow down? ....................................................... 51

3.11 Does the angle of the ant's head or body have an effect on their speed?..................... 52

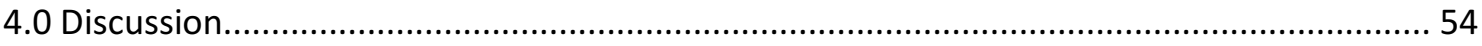

4.01 Disentangling decisions and biomechanical adaptations .............................................. 55

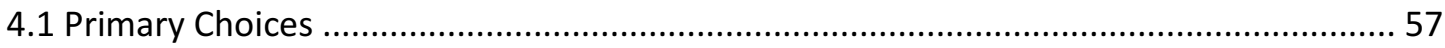


4.1.1 How does trail gradient affect the size of the ants who choose to cut? 57

4.1.2 Does the gradient affect the size of the leaf fragments which the ants choose to cut?60

4.1.3 Gradient and compensation through adjustment to the head and body angles. .63

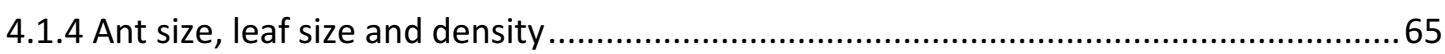

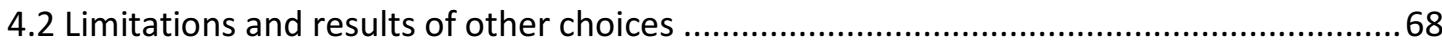

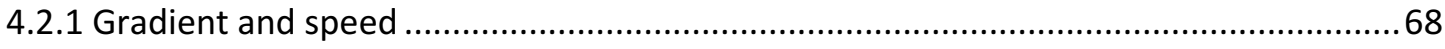

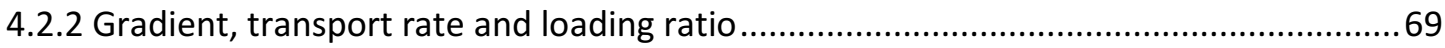

4.2.3 Gradient and compensation through adjustment to the head and body angles...........70

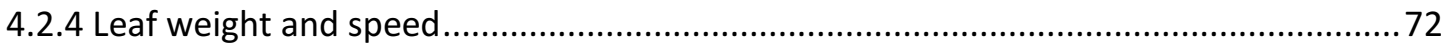

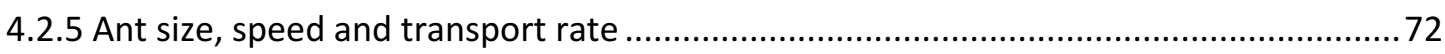

4.2.6 Adjustments to maintain stability and their effect on speed.........................................73

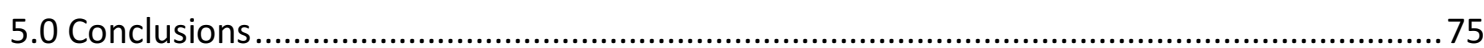

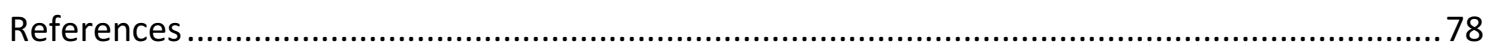




\subsection{Introduction}

Eusocial insect colonies have been described as "superorganisms" on the grounds that each individual insect can be regarded as acting like an individual cell within an organism, serving a function in the "superorganism" that is the colony as a whole (Wheeler, 1911). This has posed a challenge to ethologists as they demonstrate drastically different behaviour as a result of prioritising the colony over their individual gain.

Self-preservation is one of the greatest drivers of behaviour and to this end, an incredible array of behaviours has evolved. This can be relatively benign, such as a male lion eating his fill from a kill before allowing females to feed (Packer et al., 2001) but in times of extreme stress or scarcity, the bonds of sociality can break, such as in the case of the two-spotted Astyanax (Astayanax bimaculatus), a species of fish who will wound other members of its school in order to make them a more desirable target to predators, when they are exposed to the active search pattern of a predatory fish (Goulart and Young, 2013). At the very most extreme is filial cannibalism where the young are killed and consumed by the parent as often observed in fish (Manica, 2002), but also observed in animals traditionally considered to be caring parents, such as Sumatran orangutans (Pongo abelli) on rare occasions (Dellatore et al., 2009). In contrast, eusocial insects generally show a relative disregard for their own safety and in many cases, willingly and even deliberately give their own lives for the sake of the continued survival of the colony. Globitermes sulphurous, a species of termite, will deliberately rupture their bodies using violent muscle contractions in order to release a sticky secretion to defend the mound (Bordereau et al., 1997), while Camponotus ant species are known to similarly commit suicide by rupturing mandibular glands, releasing a spray of poisonous fluids from the head (Jones et al., 2004). It is well known that honey bee (Apis mellifera) leave their sting in the skin of large mammals at the expense of the worker's life. The detached sting releases an alarm pheromone, signalling other nest mates to defend the colony (Wager and Breed, 2000). This is one 
of the ways in which eusocial insects must be viewed as a cell (in this example, a white blood cell fighting a threat to the organism) in the super organism.

Eusociality has been defined as a state of colonial living where "two or more overlapping generations care co-operatively for the young and are divided into reproductive and nonreproductive (or at least less-reproductive) castes" (Batra, 1968). In the leaf cutting ant, Atta cephalotes, the workers are largely infertile and while they possess ovaries, they are greatly reduced and primarily used for producing food for the queen (trophic egg laying) (Dijkstra and Boomsma, 2006). As eusocial hymenopteran species have their sex determined by whether the egg was fertilised or not (haplodiploidy). In Atta, in a rare instance that a worker lays an egg (almost always in the case of colonies where the queen has died) and it actually produces a larva, it will be a male (as the workers have never mated), much smaller than a male laid by a mated queen and likely unable to mate (Dijkstra and Boomsma, 2006).

The reproductive caste in many ant species including Atta cephalotes (known as monogynous species, meaning "one queen") is a single individual, commonly known as the queen, although in other species (e.g. the Pharaoh ant (Monomorium pharaonis)) can have multiple queens (polygyny) co-existing peacefully within the same colony (Hölldobler and Wilson, 1977). When the colony is established (initially by a single mated queen in $A$. cephalotes) and reaches a big enough size and population the colony may invest in the creation of alates, the winged males and females that will eventually leave the nest on a nuptial flight. Nuptial flights are when many colonies release their alates at the same time so they can mate with other winged alates. These alates either die in the case of males or go on to found their own colonies in the case of females, though most females do not survive as these nuptial flights are capitalised upon by many predators (Peeters, 2012).

Outside of the queen and maturing sexual alates, Atta cephalotes has 3 distinct, nonreproductive castes of worker ants. The Minims are the smallest caste of ants and primarily concerned with leaf processing and cleaning, maintaining the fungal gardens 
and distribution of the fungal hyphae, though they also ride on leaves being carried by other workers as a defence against phorid flies (Vieira-Neto et al, 2006). The Mediae, the most common worker caste seen outside of the nest, take the lead in terms of foraging and waste management (Chittka et al, 2012). Lastly, the Majors are the largest caste of ant with the primary task of defence, rarely do anything else (though there is evidence to suggest that their powerful jaws are also used to cut into fruit to be transported by smaller workers (Evison and Ratnieks, 2007)). Except for the nuptial flights or disastrous events such as the colony being disturbed, the non-reproductive workers are the only ants seen above ground, with the queen being hidden and protected deep within the nest, safe from harm.

Another way in which they can be seen as a single cell in the super organism is how the adult workers care for their mutualistic fungus. The attine ants are ant species which have formed a mutualistic relationship with species of Leucoagaricus fungus, cultivating it inside specially created fungus gardens as food for their larvae (Kooij et al., 2011). This mutualistic relationship is at least 55 million years old, with the symbiont fungus becoming obligate 30 million years ago and the Atta and Acromyrmex ants emerging approximately 15 million years ago (Worsley et al., 2018). However, the adult workers derive very little benefit from the fungus, as it makes up only $5 \%$ of their diet (the remainder being fruit and plant sap (Bass and Cherett, 1995). There is even evidence to suggest that even this small amount of consumption is to aid the fungus, as enzymes contained within pass through the gut unchanged and help to prepare the substrate (leaf fragments) for fungal growth (Worseley et al., 2018).

\subsection{Contributions of The Fungal Symbiont: Leucoagaricus gongylophorus}

The primary role of Leucoagaricus gongylophorus in the relationship is the decomposition of leaf material so that the ants may take advantage of a food source which would otherwise be unavailable as they cannot digest leaves directly (Worseley et al., 2018). It does this through the production of specially evolved fungal hyphae called staphylae, which essentially function as a fruit which the ants can harvest, providing proteins and starch products to the larvae (Worseley et al., 2018). These 
staphylae make up the entirety of the diet of the larvae, which means that the adult ants derive little benefit from them but the colony as a whole requires them to replace the workers lost through predation, accident, disease or old age.

In addition to nutritional content and self-serving enzymes, the Leucoagaricus appears to have partially supplanted amino acid production in leaf cutting ants (Suen et al., 2011). In A. cephalotes, key genes for the synthesis of argenine are lacking, which indicates that the fungus, as the sole diet of the larva, are the source of this vital amino acid (Suen et al., 2011). In addition, genes coding for the production of serine proteases are extensively reduced, with the fungus doing the job of breaking down proteins (Suen et al., 2011). Additionally, unlike almost all insect species, A. cephalotes do not produce hexamerin 70c, which serves as a source of amino acids during the transition between larva and adult in most species (Suen et al., 2011). It is suggested that the ants could once produce all of these but as their mutualism with the fungus deepened, they no longer needed to so the production of these substances became an unnecessary burden and evolutionarily selected against (Suen et al., 2011).

\subsection{Contributions of The Insect Symbiont: Atta cephalotes}

Regarding their contribution to their fungal partner, the work of $A$. cephalotes can be divided into two distinct aims: maintaining the health of the existing fungal crop, preparing and implanting leaves to act as substrate for the fungal crop and the gathering of those leaves.

\subsection{Maintaining the Fungus Crop}

Maintaining the health of the fungal crop requires diligent cleaning or "weeding" of the fungus in order to remove as many pathogenic contaminants as possible (Burd and Howard, 2005). Escovopsis, a fungal parasite of the Leucoagaricus, is particularly prolific as $100 \%$ of sampled waste material by Augustin et al. (2017) were contaminated by Escovopsis and, if left unchecked, Escovopsis can completely overgrow the fungal gardens, leading to declining ant health and eventually, to the death of the entire colony (Augustin et al., 2017). The selective pressures applied to 
the ants by Escovopsis and other pathogens have led to the evolution of behaviours that minimise the risk of contamination

A. cephalotes utilise both internal refuse chambers (Burd and Howard, 2005) and external waste dumps (Hart and Ratnieks, 2001). In the case of internal refuse chambers, the chambers are physically walled off by dedicated workers who work these internal dumps and have little to no contact with the rest of the colony (Hart and Ratnieks, 2001). In the case of external waste dumps, the vast majority of waste ( $\sim 97 \%)$ is placed in a cache outside of the actual waste dump itself, rather than being directly given to waste dump workers, which minimises contact with the waste dump material (Hart and Ratnieks, 2001). Workers who work on the waste dump itself rarely try to leave and in rare instances that they do, they are aggressively forced back by nestmates (Hart and Ratnieks, 2001). This results in a system where waste material and the ants potentially contaminated by pathogens in that waste material, only leave the fungal gardens and never enter them (as the larval ants are reared within the fungal gardens), effectively separating the two entirely (Hart and Ranieks, 2001).

While the ants may try to breed a mono-culture of Leucoagaricus, there will inevitably be other fungi that get carried in or spores that travel in on the air. Many of the fungi growing in a leaf cutting ant fungal garden may not be outright parasitic to the desired Leucoagaricus, like the aforementioned Escovopsis, but they can be nutritional competitors. Depending on the species, different fungi are removed to greater and lesser extents (Currie and Stuart, 2001; Mighell and Van Bael, 2016). The response to some of the fungi can be extreme, with approximately $1 / 3^{\text {rd }}$ of the colony involved in removing Escovopsis, while the more generalist fungal pathogen Trichoderma warranted a lower, but still considerable response of $9 \%$ of the colony workforce engaged in "weeding" (Currie and Stuart, 2001). This "weeding" is achieved by licking the substrate and passing the material that is picked up through the infrabuccal pocket, which is a structure in the ant's mouth parts where spores collect. These spores can then be regurgitated in the form of a pellet, most frequently outside a 
waste dump (Little et al., 2003). The ants remove this infectious material to prevent infections in the fungal garden from spreading and maturing.

However, in the case of infections that have grown to become problematic, several minim workers will loosen part of the substrate so that a larger worker can take the infected chunk away from the fungus garden, even if that involves removing some of the crop and undepleted substrate (Currie and Stuart, 2001). The ants show remarkable plasticity in this behaviour, as they have been observed to be initially rebuffed in their efforts to remove Penicillium by the sheer amount of conidia which coated the ants, but subsequently rolled healthy substrate over the fungus so that it could be removed (Mighell and Van Bael, 2016). Following this, they would clean themselves thoroughly with the secretions from their metapleural glands and return to work (Mighell and Van Bael, 2016).

Metapleural gland secretions are important for infection control in many species of ants as they contain a wide array of anti-microbial compounds that help prevent infections, which might spread quickly in the densely populated ant colony (FernandezMarin et al., 2006). In the leaf cutting ants of Atta and Acromyrmex, this is taken a step further because these secretions are not only used on themselves and brood, but they also groom other adult nestmates with them (which is not seen in more basal genera) and the fungal crop as well to extend this protection to the Leucoagaricus fungal partner (Fernandez-Marin et al., 2006). The leaf cutting ants will also increase the frequency of their self-grooming behaviour in response to exposure to fungal conidia but not to similar substances which do not contain a fungal contaminant (FernandezMarin et al., 2006). It should be noted that this is a choice on the ant's part, as they have been see to very precisely groom the opening to the metapleural glands, rather than this being a passive and steady flow from the glands (Fernandez-Marin et al., 2006). These secretions also serve to modulate the $\mathrm{pH}$ of the fungal gardens, which makes it unsuitable for many kinds of bacterial infection and the removal of the ants from a fungal garden results in the $\mathrm{pH}$ increasing and then an influx of opportunistic fungi and bacteria (Mendonca et al., 2009). 
Not all bacteria are harmful, and some have formed deep associations with the ants, starting approximately 50 million years ago (Marsh et al., 2013). Several species of Streptomycetes, Dermacoccus and Pseudonocardia have been found growing in leaf cutting ant fungal gardens and their metabolites have been found to be effective against harmful fungi and Escovopsis in particular, while not harming the Leucoagaricus fungal crop (Haeder et al., 2009). In many species of Acromyrmex, Pseudonocardia bacteria are visible on special structures in the cuticle of the ants, in order to provide protection to the individual and as an additional step to minimise the risk of bringing infectious spores back into the colony (Marsh et al., 2013). While Pseudonocardia have been frequently isolated in Atta colonies, they do not show the same structures in their cuticle, suggesting that Atta colonies use other methods, such as the aforementioned grooming to prevent infection (Marsh et al., 2013).

Acromyrmex species have specially modified exocrine glands to produce substances to support and encourage the growth of these Pseudonocardia, which may have proven too costly an adaptation for some species, such as those of Atta who lack such modifications (Currie et al., 2006).

\subsection{Processing and Distribution}

Much like we must refine raw ore before we get usable metal out of it, the ants cannot simply take a leaf fragment, put it into the fungus garden and leave it at that, as this would not only invite dangerous pathogens into the fungus garden (such as the aforementioned Escovopsis) but also result in a slower rate of growth for the fungal crop (Mighell and Van Bael, 2016). Instead, it must first be processed and turned into a usable substrate for the fungus.

Previous studies have shown that the ants already have a preference for leaves with lower levels of endophytic fungus (Leal et al, 2014), but considering the amount and diversity of fungi in the rainforest habitats that Atta cephalotes inhabits, leaves completely devoid of fungal contaminants are incredibly rare (Arnold and Lutzoni, 2007). With the ants creating an internal environment suitable for the growth of their 
Leucoagaricus fungal crop, they also create an environment suitable for the growth of many other fungus (Moreira et al., 2003).

Once inside the nest, the fragments are taken by smaller workers into the fungal garden chambers and placed there to await pick up by other workers (Burd and Howard, 2005). The leaf fragments are then picked up by one or two workers who slowly lift it up the side of the fungus garden, all the while cleaning it with their mouth parts (Burd and Howard, 2005), during which time any existing waxy cuticle is removed from the leaf (Jaffe, 2008). Finally, after having been thoroughly cleaned and raised into position, the leaf fragment is shredded into very small fragments by tearing at the periphery of the leaf and the minim workers carefully place the fragments in the upper regions of the fungus gardens (Burd and Howard, 2005)

As for how they distribute the leaves amongst the various fungal chambers, which can number up to 8,000 in $A$. cephalotes (Roemer and Roces, 2014), little research exists, presumably due to the difficulty of performing such a study. Research using dyed bait and leaves marked with radioactive isotopes suggest that leaf fragments appear to be distributed uniformly over all sectors of the nest in Atta bispaerica, Atta capiguara, Atta laevigata and Atta sexdens (Moreira et al., 2003), though the mechanism for how this is achieved remains undiscovered.

\subsection{Foraging}

Most eusocial Hymenoptera are ideal organisms for the modelling of central place foraging theory, a theory which states than an organism will select loads which optimise the amount of food gathered over a unit of time, while returning to a central point such as a nest or burrow (Burd and Howard, 2005). Too great a load means the time taken per load will increase to such a degree that less food is gathered in the time period and too small a load will increase travel time to and from the nest, reducing the time spent actually gathering food. However, when working in a group, such as in the social insects, additional optimisation behaviours have been observed. In the case of the honey bee (Apis mellifera), workers that discover a new food source will return to 
the colony carrying a much smaller load than they are capable of, to recruit more workers and maximise the colony's overall gain (Farji-Brener et al., 2011). However, experimental studies have shown that leaf cutting ants consistently choose loads which were smaller than what would be expected for an individual to maximise its efficiency (Burd and Howard, 2005). Unlike harvester ants such as Pogonomyrmex badius, who make large underground granaries of seeds for later consumption (Tschinkel and Kwapich, 2016), leaf cutting ants must engage in additional, time consuming steps inside the nest (Burd and Howard, 2005). The harvester ants simply place the seeds in a large chamber not even bothering to break open the larger seeds and allowing them to germinate in order to get inside the hard, outer shell (Tschinkel and Kwapich, 2016). However, the leaf cutting ants must distribute their leaves to the fungal gardens, hoist them into position in the upper layers of the fungal mass and clean them with their mouthparts to remove as many potential contaminants and pathogens as possible and then shred them into very small fragments before placing them into the fungal garden itself (Burd and Howard, 2005). If they were bringing food back to the nest, then Atta as individuals would fail to optimise their foraging, but as they do not bring food but material to provide substrate for the fungal gardens, smaller loads result in faster processing times inside the colony, resulting in a greater substrate output over time than if they brought larger fragments back to the colony (Burd and Howard, 2005).

While all ants are central place foragers, sending foragers out from and returning foraged items to a central location (either a permanent nest or a temporary bivouac), they have developed a variety of search methods in order to locate food. Atta use "trunk trail foraging" (Lanan, 2014) which is best visualised as a tree. The trunk of the tree is a main foraging trail which extends away from the nest, before separating into branches and then divides further and further as the ants separate and forage individually (Lanan, 2014). The heavily used trails are kept free of debris and ants who find themselves slowed by obstruction (either traffic jams or debris) on these trails may decide to pull at the sides of the trail, which results in heavy use leading to a 
widening of this trail, which is a decision made by the individual at that point and one of the ways in which the ants must be considered individuals (Shepard, 1982). This also means that as material sources are depleted and recruitment to the trunk diminishes, use decreases and eventually the trail will narrow or cease to exist (Shephard, 1982). At the end of the trunk, the ants fan outwards and search individually. These trunks can be maintained for months or years and are often defended in a territorial fashion (Lanan, 2014). Maintaining these trunk trails represent substantial investment, as a single Atta colony may maintain 3km of these trails in a year (Farji-Brener et al., 2007), with colonies that maintained a $2.7 \mathrm{~km}$ network of trails expending roughly 11,000 antdays of work, with an energy expenditure equivalent to bringing 8000 leaf fragments back to the nest (Howard, 2001). The maintenance cost of these trails has been shown to be of utmost importance in forest dwelling leaf cutting ants, as the ants will choose trail routes that are longer, but minimise maintenance costs, while ants in more open environments preferred shorter paths, even if they required relatively more maintenance (Farji-Brener et al., 2015). This is most likely due to the higher occurrence of obstructions which must be removed due to falling leaf litter in a forest environment (Farji-Brener et al., 2015). When compared with an uncleared trail, ants move about twice as quickly over a cleared one and also expend less energy per trip, meaning that the cost of clearing such a trail can be regained over a few days in many cases (Bochynek et al., 2017).

Trunk trails mostly avoid nearby material sources in favour of taking leaves from further afield, which would at first appear detrimental as greater distance incurs a greater cost to efficiency in time and energy expenditure. However, Hart and Ratnieks (2002) noted that $92 \%$ of all foraging trails in Atta columbica moved in the opposite direction to external waste dumps, and with the current theory of Escovopsis dispersal being through water runoff from waste dumps (Augustin et al., 2017), trunk trail foraging may be preferred as it minimises search and foraging behaviour close to the nest. Despite the ants placing their waste dumps downhill from the nest when possible (Hart and Ratnieks, 2002), the risk of contamination through windblown or water 
carried spores would still be higher close to the nest, due to the proximity to the waste dump (being between $0.4 \mathrm{~m}$ and $1.3 \mathrm{~m}$ from the nest) (Hart and Ratnieks, 2002), while the risk of contamination further afield may be significantly lower, though this is unverified in current literature. It may also be the case that in the process of maturing, the ants used up all the high-quality material in the proximity to their nest and out of necessity, must search further afield to find new sources. There is also evidence which suggests the area of bare ground cleared to make the trunk of the trail serves as an organisational guide. Once ants leave the trail, their searching is individually very inefficient, so the existence of what is effectively a road, leading ants to areas known to be abundant in high quality material, increases the likelihood of an individual finding a source of material, at which point they can recruit other workers to the source (Shephard, 1982).

These trails frequently make use of fallen logs or branches (as much as $9.3 \%$ in the case of Atta columbica) as a short cut for maintenance as little leaf litter accumulated on these surfaces, while still providing a smooth surface which reduces travel distance and increases speed (Farji-Brener et al., 2007). Some ants show an even stronger preference for using falling logs, branches and lianas, that their trails can follow these objects for as much as $93 \%$ of their length, as in the case of Camponatus rufipes (Loreto et al., 2013). In a study using A. cephalotes, Farji-Brener et al., measured increases in speed as high as $200 \%$, particularly with heavily laden ants when using these fallen branches as part of their trail (Farji-Brener et al., 2007). Even a small increase in speed is important as it is multiplied thousands of times as thousands of workers use the trail. Farji-Brener et al. estimated that even 4 seconds less per $20 \mathrm{~cm}$ could result in almost a year of combined foraging time being saved per day (FarjiBrener et al., 2007). They also note that these branches are smooth, even when compared to a manually cleared trail that the ants use when no branch is available and conclude that rugosity must be an important factor in their decision making when it comes to foraging behaviours (Farji-Brener et al., 2007). This is further evidenced by the fact that the trail orientation seems to be directed by these branches, following 
them even if they differentiated from the current direction of the trail, despite the ants generally showing a preference for continuing in the same direction (Farji-Brener et al., 2007). Though this is suggested to be due to the frequency that leaves, and other material can be found at the end of fallen branches initially, only becoming part of the trail after such resources have been depleted (Farji-Brener et al., 2007). Even more evidence for the preference for smooth trails comes from observations that trail maintenance includes workers moving soil to fill holes in the trail (Griffiths and Hughes, 2010). While no research currently exists in the effect of rugosity in leaf cutting ants outside of comparing cleared and uncleared surfaces, these observations suggest it must be of significant importance. It has been shown to be important in seed harvesting ants who have been shown to more frequently drop or transfer their seeds to another worker when travelling over rough terrain (in their study, gravel as opposed to sand), which also slows travel time by between $13 \%$ and $51 \%$ (Bernadou et al., 2011).

The efficient gathering and distribution of leaves is vital for the continued survival of the fungal crop and by extension, the entire colony as without the continuous replacement of lost or dying workers by larvae maturing in adults, the colony will die. However, as mature Atta colonies can consist of millions of individuals (Rudolph and Loudon, 1986) and up to 8,000 chambers (Romer and Roces, 2014), the ants require a novel system for both locating and gathering the sheer quantity of leaves required to sustain such a large fungal crop (up to 500kg (dry weight) annually (Leal et al., 2014)). The leaf cutting ants consume so much leaf material that they have become the preeminent herbivores in the Neotropical region, a niche which is normally filled by large herbivorous mammals in most habitats (Leal et al., 2014).

Leaf cutting ants are extremely polyphagous, being able to utilise $50 \%$ of all local plant biomass, including leaves, twigs, bark and seeds (Wirth et al., 2003) and have the potential to harvest up to $40 \%$ of leaf production in an area (Leal et al., 2014). The rainforests which the ants inhabit have no shortage of suitable material for the fungal gardens and with no risk of being unable to gather the sheer quantity required, the 
ants can afford to expend time and effort to select only the highest quality materials which will make the best substrate for the fungal crop. The ants demonstrate a preference for leaves from long lived plants such as large trees, young leaves, fruits and flowers, drought stressed leaves, leaves from plants with few defences (both physical and chemical) and leaves with low quantities of foliar endophytic fungi (Leal et al., 2014). With these stringent criteria in place, the ants must be able to efficiently gather from leaf material sources which meet their high standards.

Once a source of leaf material has been located, the ant assesses its quality. This is where we must consider the ant not as a cell in the super organism, but as an individual because that individual makes a determination as to whether the leaf material is of sufficient quality to be worth collecting (Leal et al., 2014). If it is not good enough, the ant can simply move on but if the ant decides that the food is good enough, it must arrange for transport back to the nest. It could simply cut a fragment, take it back and then come back for more but what actually happens is the mass recruitment of other workers to accelerate the process (Jaffe and Howse, 1979).

Some species of ant use a method called "tandem running" in which the discovering ant physically leads a single nest mate to the food, who can then do the same (Franks and Richardson, 2006). Some utilise group recruitment in which as many as 30 ants might be led to the food source (Planqué et al, 2010). These methods seem to be most prevalent amongst small colonies (Planqué et al, 2010). Atta cephalotes utilises a method of volatile pheromone trails which can not only recruit additional ants to exploit the food source, but also indicate direction and the quality of the leaves by modulating the concentration of pheromone on the trail (Jaffe and Howse, 1979).

Atta cephalotes uses methyl-4-methyl-pyrrole-2-carboxylate, though other pheromones and even cocktails of different pheromones have been recorded in other species (Jaffe and Howse, 1979). This pheromone attracts other ants to it, resulting in more ants discovering the leaf material who then make their own judgement of its 
quality and if they also deem it to be of sufficient quality, they will lay a trail back, increasing the concentration of pheromone on the trail (Jaffe and Howse, 1979).

This results in an exponential increase in the number of workers at a food source, until it is so saturated with ants, that new workers following the trail can no longer gather from that source and therefore, do not elect to lay their own pheromone trail behind them (Jaffe and Howse, 1979). Due to the volatility of the pheromone, if the trail is not constantly reinforced by returning workers, then the trail dissipates and can no longer be followed by other ants, meaning that they simply cannot waste energy following a trail with no pay off at the end of it (Jaffe and Howse, 1979). In short, the pheromone system means that the number of ants at a source of material increase rapidly until an optimum number of gatherers is reached, and as that food source is depleted, the number of workers will decline as fewer workers will lay their pheromone and the trail will become less attractive, ensuring that the optimum number of workers are assigned to the task at any point, without any kind of central command system (Jaffe and Howse, 1979).

Relying on personal judgement would initially sound like it could result in errors but the reliance on other nestmates reinforcing the trail to make the trail strong enough to attract a large swarm, means that many ants must check the leaf material for quality, resulting in a minimisation of these errors.

\subsection{Known factors considered at the foraging site}

At the foraging site, the ants must make two decisions. Firstly, as an individual, it must decide whether the leaves at this site are worth taking back to the nest at all. Secondly, they must decide how big a load to take.

A. cephalotes is a highly polymorphic species of ant (Burd, 1995) and even amongst mediae workers who do the bulk of the foraging, there is still considerable variation in size. Each load must be considered by the ant that seeks to carry it, as a small worker would be more easily overburdened than a larger worker. Overloading of an individual ant will result in slower transport rates and this can have a knock on effect to other 
ants on the trail as they are stuck behind an overloaded worker and unable to pass (Farji-Brener et al., 2011). As ant trails with greater ant flow tend to have fewer overladen ants, it has been suggested that the ants deliberately take lower loads than they are capable of in order to avoid causing such delays as this has the potential to increase travel time for hundreds or even thousands of other ants (Farji-Brener et al., 2011). A. cephalotes sometimes uses a co-operative technique in which leaf fragments are cut by some workers before being placed in a cache for other workers to pick up (Roschard and Roces, 2003). In this case, each ant decides whether to cut or carry, based on factors such as leaf density, the existence of tough or waxy layers on the leaves, their own size and the integrity of their mandibles and assumes the role for which it is most suited (Nichol-Sorians and Schultz, 1989; Roschard and Roces, 2003; Schofield et al., 2011).

While A. cephalotes can make use of a wide array of plant material (Wirth et al, 2003), experiments and observations have shown that certain traits are particularly attractive to the ants. These preferences have presumably evolved due to greater yields of fungus when grown on these kinds of substrate, allowing for faster colony growth, enabling them to outcompete other colonies and to better resist attacks from species such as Nomamyrmex esenbeckii, a soldier ant species which specialises in attacking $A$ cephalotes (Swartz, 1998).

The first is that leaves from long lived sources such as trees tend to be favoured over short lived or annual plants (Leal et al, 2014), as are flowers and fruits which are more energy rich than bark or leaves (Falcao et al., 2011). Unsurprisingly, plants with few or no induced defences (Kost et al, 2011), chemical defences (such as insecticide poisons like caffeine) (Falcao et al., 2011) or physical defences are also favoured (NicholsOrians and Schultz, 1989), due to a lesser cost in terms of collecting from the source. They also favour leaves from young plants (Mundim et al., 2012) and drought stressed leaves (Ribeiro Neto et al., 2012), presumably due to an increased or more concentrated nutritional content which would accelerate fungal growth. 
They also show a preference for leaves which have a low concentration on endophytic fungus (Van Bael et al, 2012). These endophytic fungi are problematic for two reasons. The first reason is that these fungi have the potential to be competitors or parasites for the Leucoagaricus fungal crop and although the ants will take them, they spend up 30$43 \%$ longer to cut, carry and clean leaves which had either a high concentration or high diversity, which would reduce transport rate and overall fungal yield, due to lower volumes of substrate being brought into the nest (Van Bael et al, 2012). The second is that some of these species of fungi modify the leaf chemistry to contain low volatility compounds which are released when the leaves are wounded (such as when a leaf cutting ant cuts into them) (Estrada et al, 2013). These compounds appear to influence leaf cutting ant foraging decisions and deter the leaf cutting ants from cutting further, though whether the compounds themselves are harmful to either the ant or fungus or whether these compounds simply indicate to the ants that they contain fungus that is potentially harmful or competitive to the Leucoagaricus is unknown (Estrada et al, 2013).

Interestingly, new plants which the colony has never encountered before are also favoured (Saverschek et al., 2010). Initially, this might be seen as a risky move on the ant's part as the plant could have many disadvantages, ranging from simply being poor nutritionally to containing powerful fungicides which would damage the fungal crop. However, the ants removed any unsuitable material within 48 hours and subsequently, those plants are avoided (Saverschek et al., 2010). The ants may simply be experimenting with new sources of substrate material in case it is better for the fungus while being able to remove anything that has adverse effects. The uniform distribution of leaves observed by Moreira et al (2003) may also serve to minimise the dose given to each fungal garden, limiting both the damage to any particular fungal garden and ensure that there will be healthy fungus from which to grow a new one if the entire fungal garden is destroyed by a contaminant. The avoidance effect induced by this persisted for as much as 18 weeks, suggesting the ants have a surprisingly robust memory (Saverschek et al., 2010). 
With this demonstrated memory, leaf cutting ants certainly have the capacity to remember the trail and their construction of large trunk trails indicates that they do consider the trail as a factor, but the length of the trail does not appear to be something that the ants consider when deciding which leaves to cut (Wetterer, 1991). However, later that same year, Shutler and Mullie found that workers who travelled long distances to leaf material sources were both larger and carried larger loads back. Larger loads when travelling a longer distance makes sense due to the simple virtue of maximising the profit from a trip, but they discovered that the larger loads were entirely down to the workers who decided to cut being larger (Shutler and Mullie, 1991). The workers did not modify the load they carried when collecting from closer sources so they proposed that the larger workers could both handle more weight and cover more distance in a single step, resulting in a faster travel speed and transport rate (Shutler and Mullie, 1991).

This acknowledgement of each individual ant's limitations extends to whether or not they cut as well as carry. The mandibles are the cutting apparatus used to cut fragments from leaves and like any tool, they become worn with use (Schofield et al., 2011). As might be expected when working with a blunt tool, when ants with worn mandibles choose to cut, they cut more slowly (up to $44 \%$ slower) than workers with pristine mandibles and also incur a much higher energy cost (Schofield et al., 2011). As a result, it seems that workers with worn mandibles try to cut, experience difficulty and instead stop cutting and revert to a carrier role, with those with the most worn mandibles rarely even attempting to cut and instead, exclusively carrying leaves back to the nest (Schofield et al., 2011). This change in behaviour serves to not only increase efficiency at the foraging site, since workers who struggle to cut won't be taking up space which other workers can use, but also to increase the useful lifespan of each ant, ensuring the colony gets the greatest return on the energy invested in rearing each individual (Schofield et al., 2011). Currently, it is unknown if worker age plays a role in this behaviour or if it is purely down to the difficulty experienced at the foraging site (Schofield et al., 2011). 


\subsection{Decisions and adaptations on the trail}

While the length of the trail may be unimportant, it appears that the amount of traffic (other ants) on the trail is important. When the traffic on the trail is light, the ants seem to cut larger leaf fragments with little regard for whether they might slow down the flow of ants on the trail (Klok, 2011). However, when the traffic is heavier, the ants avoid overburdening themselves in order to avoid delays caused by an ant with too big a load from creating a bottle neck on the trail (Klok, 2011). This shows that the ants are fully capable of estimating the amount of traffic on the trail and adapting to it in order to ensure smooth transit on their return trip, demonstrating the ability to think ahead and plan for the future (Klok, 2011).

There is also the behaviour described as caching, in which leaf cutting ants will drop their leaves at the nest entrance, the foraging site and at certain points along the trail, usually points of disturbance (such as a human made track and an ant trail crossing), changes in gradient and changes in the ease of travel (Hart and Ratnieks, 2001). It seems that caches form outside of the nest when the rate at which leaves are transported to the nest exceed the capacity to process them within the nest, and rather than waste energy and time by holding the leaf until it can be processed, they simply cache it at the entrance to the nest, freeing the ant carrying it for other duties (Hart and Ratnieks, 2001). Similarly, points on the trail where the speed of workers will change, such as at the boundary of a steep slope, will sometimes form caches because of the mismatch between ants coming in and the speed at which they can progress, which makes it more efficient to cache the leaves and have them retrieved by other workers (Hart and Ratnieks, 2001). An alternative solution to this problem has been observed in $A$. cephalotes at the point at which trunk and side trails meet, where ants will directly transfer leaves to one another, to maintain leaf transport while not disrupting the flow on the main trunk trail (Hubbel et al., 1980). It may also be the case 
that the ants which know the way to the foraging site will be faster than new, naïve ants from the trunk trail, ensuring faster transport rates through familiarity.

Larger ants have been observed forcibly removing loads from smaller, overburdened ants (Wetterer, 1994). As ants carrying loads too great for them will slow down and potentially slow other ants on the trail, larger ants observe them and if they decide that the smaller ant is moving too slowly, they will attempt to take the leaf fragment from them (Wetterer, 1994). This may be similar to how ants that find themselves slowed on the trunk trail will pull at the sides of the trail, widening it (Shephard, 1982) and if so, demonstrates the ability of individuals to problem solve without external input, by identifying and then solving the problem.

Gradient is also likely to be an important factor in decisions made on the trail and at the foraging site, due to the difficulties imposed by steep gradients.

\subsection{Gradient}

Individual ants have been shown to experience increased energy costs through monitoring $\mathrm{CO}_{2}$ production in a sealed environment, on both up and downhill gradients (Holt and Askew, 2012). However, the effects of carrying a load on a vertical surface, which will inevitably pose difficulties due to the pull of gravity no longer pulling it towards the ants' feet, and the ants' adaptations to this remain largely unexplored. Previous work detailing the effect of trail gradients in Atta is restricted to three studies: Lewis et al's (2008) study on the leaf cutting ant Atta cephalotes, Moll et al.'s (2010) study on the grass cutting ant, Atta vollenweideri and most recently, Norton et al's (2014) study on Acromyrmex octispinosus.

Lewis et al.'s work focused entirely on the effects of gradient on transport rate (defined as grams per second), and on load size selection by loading ratio (being defined as (ant mass + load mass)/ant mass) which, while useful, are derived from other, unreported data such as ant mass, load mass and speed, which are also useful in understanding the decision making processes. In addition, the way the ants carry the leaf fragments and leaf size (measured as area, rather than mass) are completely 
unreported, and as balance is such a concern for any organism carrying a heavy load and the possible concern of wind resistance, represent important decisions which must be made by the ants.

Their study involved two phases: manipulations of gradient with eight wild colonies in Costa Rica and a captive colony, originally from Trinidad (Lewis et al., 2008). The field study involved removing laden ants from their trails and transferring them to a horizontal runway. Once the ant was situated, the runway was rotated to the desired angle, at $18^{\circ}$ intervals between $-90^{\circ}$ (vertically upwards) and 90 degrees (vertically downwards). As the ant travelled at this new angle, it was timed with a handheld stopwatch and its speed calculated by measuring the distance it travelled against marks on the runway. Both ant and leaf were then returned to the laboratory and measured using an analytical balance to an accuracy of $0.0001 \mathrm{~g}$.

The study using the captive Atta cephalotes, involved a 1 metre length of bamboo garden cane which has been "roughened with coarse sandpaper" (Lewis et al., 2008). The degree of this roughening was not defined. This cane was then used to link a foraging platform where the ants were provided a continuous supply of fresh privet (Lugustrum vulgare) shoots from the same plant, and the foraging platform was raised or lowered to provide a range of angles for the bamboo trail, those being $90^{\circ}, 45^{\circ}, 0^{\circ}$, $45^{\circ}$ and $-90^{\circ}$. Once a foraging trail had been established, laden ants were observed and timed, before being collected with their loads and weighed in the same way as the wild colony.

Both parts of the experiment have potential experimental issues. In the wild colony, the ant being picked up and then placed onto an unfamiliar surface, which is then suddenly rotated, is a situation which seems likely to cause confusion and disrupt natural behaviours, potentially causing the ant to behave as if under threat, seeking safety. They also mention that ants which moved less than $5 \mathrm{~cm}$ were not taken into account, indicating that some ants simply stopped or moved very little. Being stationary is not behaviour that would be observed under normal conditions on the 
heavily trafficked trail. In the laboratory study with the captive colony, the garden cane also raises issues. The width is not mentioned, meaning that it is unknown how curved the surface that the ants were walking on is and the fact that it is curved introduces another factor which the ants must take into account. The degree of roughening with sandpaper is not defined either, though one assumes that it was to create a surface which the ants could more easily grip, rather than altering the shape significantly. The ridges along the bamboo surface at growth nodes present areas of difficult terrain which must be negotiated and need to be taken into account. Finally, bamboo canes have a degree of flexibility and they make no mention of any supporting structure, meaning that the angle may not have been constant all along the path.

Moll et al's study in 2010, used a much more robust method and aimed to determine whether the ants could manipulate their load on the move to provide greater stability. Grass cutting ants such as Atta vollenweideri cut grass in much the same way as the leaf cutting ants cut leaves, but in greater lengths, often exceeding the ants own body length several times over (Moll et al., 2010). They carry the rectangular fragments of grass primarily upright, but at a slight angle over the back of the ant. This ensures that the centre of mass remains in a location where three legs of the ant are sufficient to prevent toppling (Ting et al., 1994). However, using this method, long grass fragments would shift the centre of mass further backwards, possibly even behind the hind legs, which would reduce stability and result in toppling (Moll et al., 2010). Additionally, while the environment that Atta vollenweideri occupies is generally flat, the ants still have to carry over inclines that would again modify the centre of mass, which would require the ants to be able to correct this shift (Moll et al., 2010). They hypothesised that this was achieved through angling of the head, carrying the grass fragments at steeper angles to bring the centre of mass back to within a supportive tripod of legs (Moll et al., 2010), as the ants use an alternating tripod gait where 3 legs are always on the ground (Zollikofer, 1994).

To test this gait hypothesis, a large colony was provided with paper fragments with the same mass $(5 \mathrm{mg})$ and width $(2 \mathrm{~mm})$ but differing lengths $(15 \mathrm{~mm}$ and $30 \mathrm{~mm})$ and 
thicknesses to ensure the mass was equal, even when the size was not. To make the paper fragments attractive to the ants, they were soaked in orange juice for an hour and then dried, as this was a tried and true method that had previously been used in field studies (Roschard and Roces, 2003). The ants were presented with a setup which lead through several areas. The first was a plastic tray, with dividers which ensured the ants had to walk a distance of $4.5 \mathrm{~m}$ before reaching the next area and they were allowed to explore this for several days. A wooden bridge then led them to one of two roughened Perspex trails (trail A). Roughened Perspex was chosen as the ants seemed to have difficulty gripping these trails with their claws and the focus of the study was on how the ants compensate, rather than how their claws allow them to prevent falling. This trail then led to a movable wooden bridge section, which could be crossed to a feeding area, where the paper fragments were randomly placed. The second of these Perspex trails (trail B) was disconnected most of the time, but was overseen by three high speed cameras. At the beginning of the experiment, ants would be allowed to walk over the feeding area baited with dog rose leaves, for approximately an hour and trail B was connected, to allow the ants to lay pheromone trails. The actual paper fragments were later added and trail A reconnected. Individual ants crossing the bridge, with and without paper fragments, were shifted to trail B as the bridge was moved to force them down trail B without any need for intrusive repositioning and this system also allowed them to discount significantly larger or smaller workers carrying leaves, so as to eliminate body size as a factor. The ant then walked down trail B, in front of the three cameras and were collected at the end of the trail for weighing. When a baseline for a flat trail B was achieved, trail B was replaced by a trail with a $20^{\circ}$ incline, $0^{\circ}$ horizontal sections and then a $20^{\circ}$ decline, with cameras overseeing each section. In addition, they tested whether the ants were able to adjust to a change in load, by adding droplets of viscous honey to the ends of the fragments.

Using this method, they were able to provide compelling evidence that the ants did indeed alter the angle of their heads in reaction to inclines and declines, though they did note that even unladen workers showed similar reactions, speculating that it 
served the dual purpose of both balancing the load and allowing them to direct their vision along the trail better (Moll et al., 2010). The experiment also showed that the grass cutting ants operated close to the limits of stability, as laden ants fell over fairly frequently (11 out of 37 ants, carrying long fragments), while unladen workers didn't fall over at all (Moll et al., 2010).

Finally, the 2014 study by Norton et al. used Acromyrmex octispinosus, foraging through a tube attached directly into the fungal garden chamber leading to a wooden cane to test gradients of $0^{\circ}, 90^{\circ}$ and $-90^{\circ}$ (Norton et al, 2014). Their primary stated aim was to confirm the results of Lewis et al (2008) and to see if they would get similar results with $A$. octispinosus. They also extended the project by taking foraging laden workers and also allowing the ants to form an established trail for 24 hours before taking workers and leaf fragments to see if any difference occurred between new and established trails (Norton et al, 2014). They confirmed Lewis et al's findings, but as with Lewis et al, the limited angles tested mean that opportunities were missed for a more comprehensive data set. The other potential experimental flaws in Lewis et al's work were also present, although some improvements were made by using a wooden cane instead of a length of garden cane, which would presumably eliminate potential errors caused by the ridges of the bamboo (Norton et al, 2014). However, the diagram they include indicates that the tube was inserted directly into the fungus chamber and this has the potential to be regarded as an intruder, as well as have workers which would normally not be foraging move onto the trail, both of which could potentially affect the experiment. The limited scope of the experiment also meant they provided no data in regard to head angles or adaptations beyond load mass and loading ratio.

Overall, these studies while valuable in their own right, leave gaps in our knowledge of leaf cutting ant choices on the trail. The work of both Lewis et al and Norton et al, have potentially critical experimental flaws, which raise questions as to the legitimacy of their results. While the method employed my Moll et al. was far more robust, their study was concerned with grass cutting ants, which face different challenges to their leaf cutting relatives. Furthermore, the limited scope of these studies means that the 
adjustments made leaf cutting ants like Atta cephalotes to maintain balance are completely unexplored, despite being of potentially critical important to overall foraging efficiency.

\section{7 - Aims}

With this in mind, this study has four primary aims. The first is to address what I believe to be flaws in the method employed by Lewis et al (2008), to produce more accurate data on the topics they report and to provide data which they didn't report, such as raw load mass.

The second is to examine decisions made while foraging in response to changing gradients, assuming that the ants do take the journey into account when deciding whether they should cut and how big a fragment to cut. This should be taken into account as a struggling ant has the potential to not only slow down an individual, but also other ants who would otherwise be stuck behind it.

The third is to examine adaptations made on the trail itself to examine how the ants carry their loads in detail and examine the ways in which leaf cutting ants adapt their load carriage to the trail. This will be compared to the work of Moll et al. by using a modified version of the method they used when examining grass cutting ants.

The final aim is to re-examine the ants' priorities when faced with a journey with a higher risk of losing the load. While previous studies have shown that ants will take longer routes if it means that they can maximise speed (Farji-Brener et al., 2007), speed carries risk, which should increase with steeper gradients. If this risk causes the ants to change their priorities, then it would have profound implications for our understanding of ant foraging organisation. 


\subsection{Methods}

\subsection{Study colonies and husbandry}

Three colonies of Atta cephalotes (collected in 2016 in Trinidad under license by A. Stephenson (Hart pers comm)) were used in this experiment. The colonies ranged between 15,000 and 18,000 individuals (calculated by approximating 4,500 per 1000 $\mathrm{cm}^{3}$ of fungus garden (Hart pers comm)) and were housed individually in glass tanks measuring $600 \mathrm{~mm} \times 300 \mathrm{~mm} \times 380 \mathrm{~mm}$. These tanks contained several centimetres of water and within each tank was an acrylic platform $(300 \mathrm{~mm} \times 180 \mathrm{~mm})$ on acrylic legs (measuring $120 \mathrm{~mm}$ ) forming an "island". The water in the tank was mixed with detergent and served as a barrier to prevent the ants escaping and also as a source of water vapour to maintain humidity. The tanks were lidded with 5 plastic panels that could be arranged to mostly seal the tank or to create gaps and allow water vapour to escape as needed.

On top of the platforms within the tanks, the ants were provided with either plastic boxes or upturned glass beakers in which to make their fungus gardens and the limited volume, in addition to limiting the provided leaves served to limit the size of the colony. The fungus garden volumes Colonies A and B had fungus gardens of $3,360 \mathrm{~cm}^{3}$ and colony $\mathrm{C}$ had a fungus garden volume of $4000 \mathrm{~cm}^{3}$. These tanks were placed on heat mats, which alongside small aquarium heaters in the water, served to both maintain the temperature at around $28^{\circ} \mathrm{C}$ and humidity at around $90 \%$. The room was also maintained at approximately $24^{\circ} \mathrm{C}-28^{\circ} \mathrm{C}$. These are the optimum conditions for maintaining Atta in the laboratory (Hart pers comms) and closely mimic the conditions within their natural range (Hölldobler and Wilson, 1990).

In the laboratory, the ants will cut many different leaves including bramble (Prunus), lime (Tilia) and Brussel sprouts (Brassica oleracea). Throughout this study, each colony was provided with a handful of common privet (Lugustrum vulgare), placed directly on the platform three days a week. Leaves were always provided after any daily studies had been concluded. 


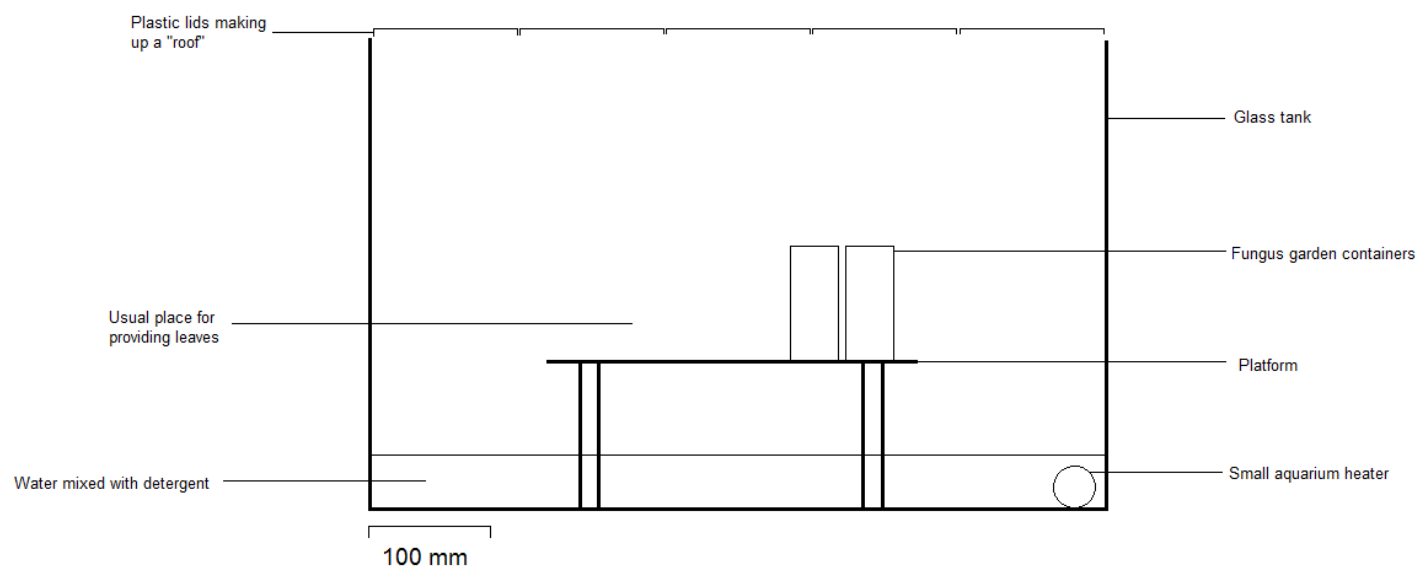

Figure 1: The tanks and platforms on which the ants were kept.

\subsection{Foraging trail set-up}

Ants were able to forage outside of the main housing tank via a foraging trail bridge which could be elevated or declined to produce different trail gradients. The trail was constructed out of two, 1-meter long wooden rulers bolted together through the use of a third ruler that was placed beneath the two rulers that made up the trail. This third ruler also presented additional angles and obstacles to the ants, which encouraged them to walk on the desired side of the ruler. The bolts were screwed in far enough, and slightly countersunk, so as to pose as little obstacle to the ants as possible.

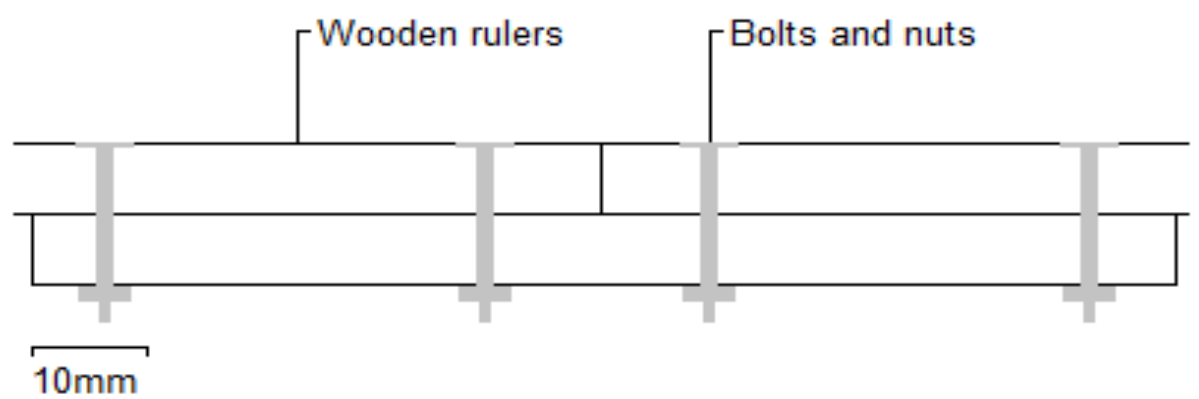

Figure 2: Construction of the wooden trail using 3 wooden rulers, screws and bolts. 
The trail was not roughened unlike in some other studies (Lewis et al, 2008), as the wood grain already provided enough of a rough surface as to cause no grip problems to the ants. The two-meter span was chosen as this enabled a full range of angles without hitting the ceiling or floor of the laboratory and also represented a distance that it was believed would affect decision making, as too short a trail might not be worth adapting to.

The trail was suspended using standard lab clamps and stands. Though the ants could climb on these stands and clamps, any trails formed ultimately led to nothing except the trays of water which were placed beneath the entire set up to prevent escape. Any ants which fell off were left in the water until the conclusion of the experiment, at which point the survivors (which were the vast majority) could be rescued and placed back on the colony platform. At the end of the trail, a plastic tray containing approximately 10 grams of privet was placed, clamped to another burette stand, at the appropriate height. The test colony was removed from the tank and placed in a tray of water at the other end of the trail. Either the colony or feeding platform was then elevated to the appropriate height for the angle desired, which was measured using a protractor against a known angle (either the flat desk edge $\left(0^{\circ}\right)$ or a door frame $\left(90^{\circ}\right)$ ). Any error resulting from this would have been slight $\left(<3^{\circ}\right)$ as the clamps were tightened as much as possible before moving. Finally, wooden lollipop sticks were used to create bridges between the colony platform, trail and feeding platform, always at a less extreme angle than the one being tested. These bridges measured a maximum of $10 \mathrm{~cm}$. A Canon Legria HF200 video camera was set up at the mid-point, so that the ant's speed could be calculated, as well as the angles and body measured. 


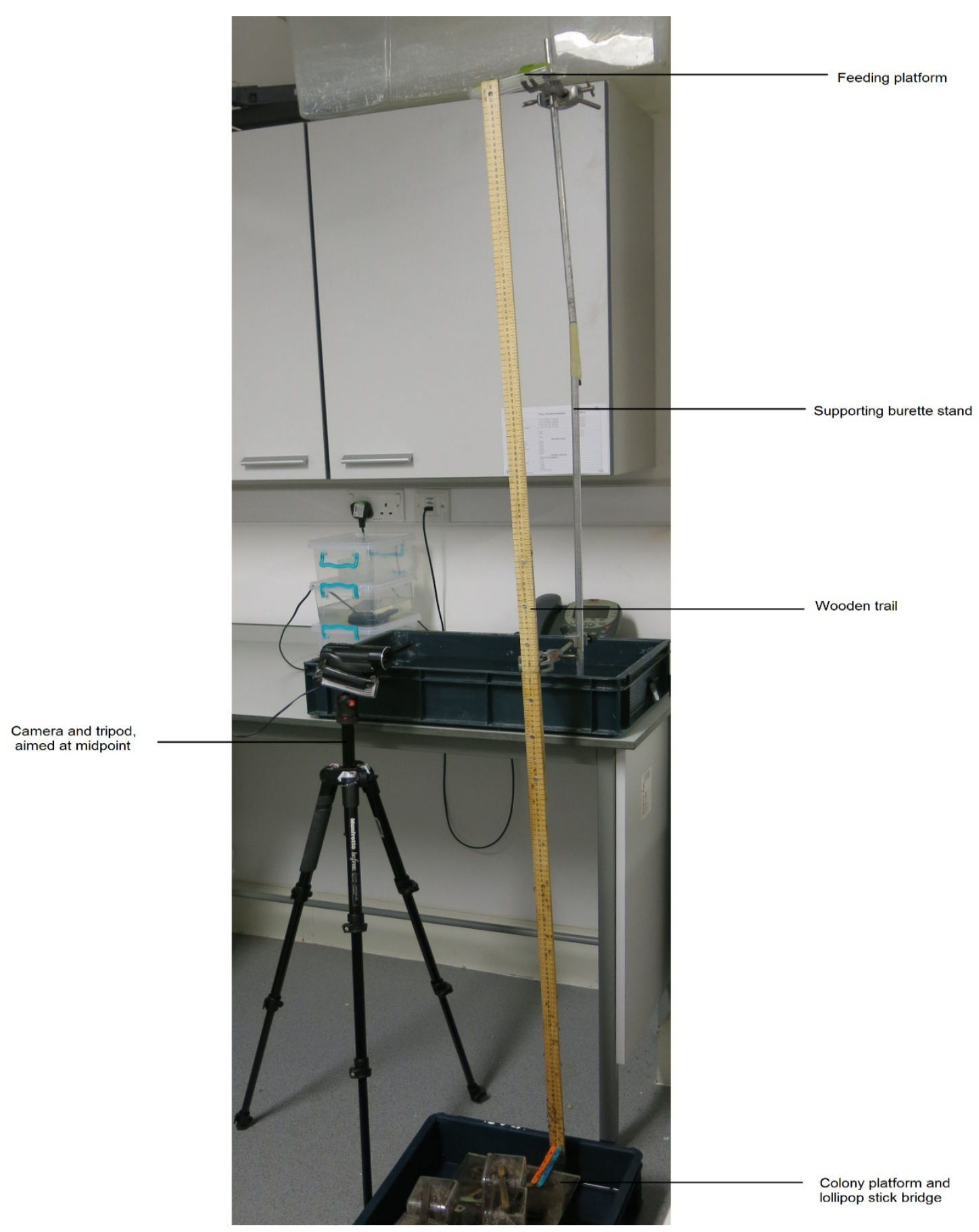

Figure 3: Example of experimental set up, this example at $+90^{\circ}$ (feeding platform vertically above the nest). The lollipop bridge is placed directly on the ant's habitation platform and ants usually began exploring it almost immediately. The trail then leads them to the foraging platform at the desired gradient, while the camera aimed at the midpoint, recorded everything at $25 \mathrm{fps}$. At all times, all potential avenues of escape were blocked by trays of water. 


\subsection{Experimental procedure}

In total, 55 experimental runs were conducted on 55 days between March and June 2019. Eleven different gradients were tested: $0^{\circ}, 18^{\circ}, 36^{\circ}, 54^{\circ}, 72^{\circ}, 90^{\circ}$ uphill and downhill equivalents. For each gradient, 5 tests were conducted. Three tests at each gradient used Colony $\mathrm{A}$ and then an additional test using Colonies $\mathrm{B}$ and $\mathrm{C}$ respectively.

During these experiments, the first three laden ants were allowed to complete the journey back to the nest, in order to ensure that a complete trail was laid. This was done because currently available information differs as to whether leaf cutting ant foraging actually changes over time (apart from an increase as a result of trail pheromone being laid), with some reporting that it does (Dussutour et al., 2007) and others reporting no change over time (Burd, 2000). For this reason, I chose to allow the ants to form a trail to a limited supply of leaves, unlike Lewis et al (2008) who chose to give them an ad libitum supply of leaves, limiting them by the amount of time they had to forage instead.

After a foraging trail had been established (typically taking 10 - 20 minutes), every laden ant that walked on the desired side of the ruler (and thus, able to provide the measurements required) was collected along with their loads, with the exceptions of majors, ants with passengers riding their leaves and the rare cases where several ants tried to carry the same leaf or leaf fragment. The ants were collected by grabbing hold of the leaf or the ant itself with entomological forceps and lifting them directly, and cleanly, from the trail. This caused minimal disturbance with any disturbance being extremely short lived and extremely localised, usually only disturbing ants within a few millimetres of the collected ant and visible disturbance ceased within a few seconds. In instances where another nestmate attempted to "save" the collected ant by grabbing hold of it, that additional ant was also removed and placed into a separate specimen jar. Each ant collected was placed immediately into a specimen jar and the lid closed. This continued until 30 ants had been collected or until there were no more leaves to collect, after which the experimental run ceased. In total, 1556 ants were collected over the course of this experiment. 
After this, the ants were placed into a freezer at $-18^{\circ} \mathrm{C}$ for three minutes, which rendered them immobile but did no lasting harm, with the ants returning to normal after about 10 minutes in the lab. This is standard procedure for handling and measuring live Atta and other ant species (Adam Hart pers comm). The ants were then weighed on a Satorius four place electronic balance, placed back into the specimen jars and allowed to regain full mobility before being put back onto the colony platform, which at this point had been returned to its tank. Their leaf fragments were also weighed on the same balance and photographed before being disposed of. Cut leaf fragments would later have their area determined from the photographs using ImageJ. On occasions where the collected ants had begun cutting the leaves into smaller fragments while the experiment continued, each fragments area was calculated individually and totalled to give the area of the original leaf fragment cut from the foraging site. The video was analysed, frame by frame to determine speed.

Interactions with other ants were removed from the analysis by subtracting the frames where they remained stationary. The video was shot at 25 frames per second, giving an accuracy of 0.04 seconds.

\subsection{Adjustments in head and body angles}

Head and body angles were determined by taking frames from the video where the subject was clearly visible and measured using ImageJ. These angles were measured against a horizontal plane and then the angle of the trail was added or subtracted as appropriate in order to give an angle relative to the trail. The profile view of the ant's heads were measured from the mandibles to the back of the head and the body was measured from that same back of the head point to the end of the mesosoma as the ants had a tendency to curl the gastor beneath themselves to make pheromone trails. Each of these lines were measure against a horizontal plane from the camera's point of view to give angles $A$ and $B$ (see figure 4 ) and then the trail angle was added or subtracted as appropriate to give the ant's angle relative to the trail. The adjustment at the ant's neck (angle C) was calculated using the equation:

$$
((180-A)-(180-B)) *-1
$$




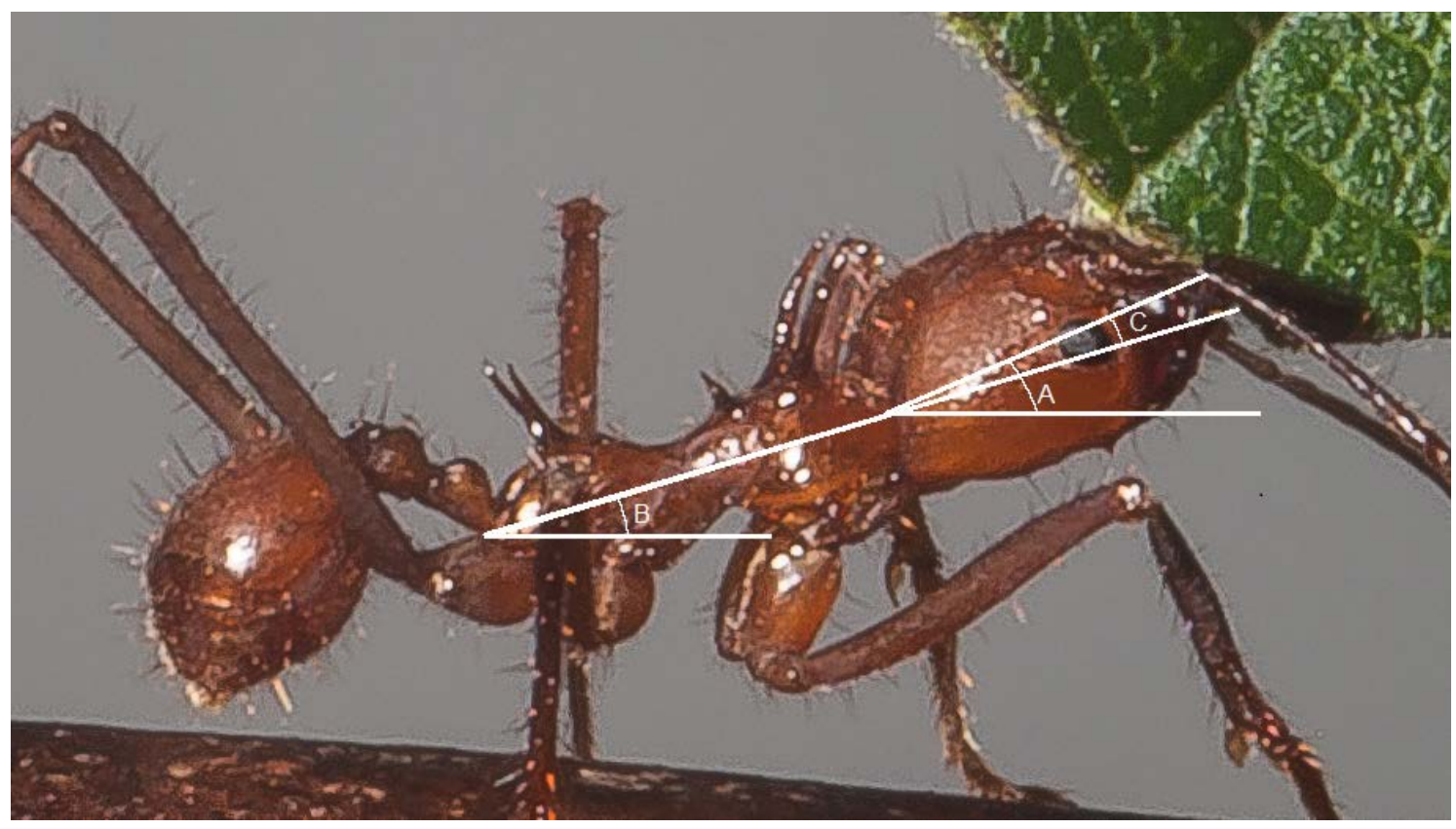

Figure 4: Demonstration of how angles were measured in this experiment. Original photograph supplied by Peter Traub. Angle A is calculated by finding the difference between a horizontal plane and a line drawn between the ant's mandibles and the back of its head. And B is calculated by drawing a line from the same point at the back of the head, to the end of the ant's mesosoma and a horizontal line. These can then be mathematically adjusted to compare to the trail. Angle $C$ is then mathematically calculated using the equation stated on the previous page. 


\subsection{Results}

In total, 1556 ants were collected over 55 tests, but 57 had to be removed from the data set due to being majors $(\mathrm{N}=27)$, bringing back loads which measured $0.000 \mathrm{~g}(\mathrm{~N}=$ 9) on the $4 \mathrm{dp}$ balance (which caused errors in the equations for loading ratio) or rare instances of having stolen the leaf being carried by another ant $(N=9)$, leaving 1499 ants in total. The 55 tests consisted of 5 tests at each gradient, with 3 tests on Colony $A$ and 1 test for Colonies B and C respectively. Of these, 1281 ants yielded video footage in sufficient detail to accurately measure the angles at which they held their heads and their bodies while transporting leaves, without other ants blocking the camera's view of them or travelling on the far side of the ruler, out of the camera's view.

Throughout this analysis, gradients where they transport leaves uphill from a feeding platform situated below the nest are referred to as positive and gradients where they transport leaves downhill from a feeding platform above the nest are referred to as negative. For example, if the feeding platform is placed directly above the nest, the ants carry leaves they have cut vertically downhill from the feeding platform and this is referred to as $-90^{\circ}$.

\subsection{Does trail gradient affect leaf transport rate?}

The data were not normally distributed (Shapiro Wilk test: $P<0.001$ ). Therefore, the data were analysed using a Kruskal-Wallis test on the transport rate data by gradient and was shown to be significantly affected by the gradient of the track when analysing the entire data set $\left(X^{2}=152.699, d f=10, P 0.001\right)$. Additionally, visual inspection of the data (see figure 5) suggested that uphill and downhill gradients were affected differently, with uphill gradients resulting in a much higher decrease in transport rate than downhill gradients. Consequently, both uphill and downhill gradients were separated and also analysed using a Kruskal-Wallis test, including $0^{\circ}$ in both data sets (Uphill: $X^{2}=112.260, d f=5, P 0.001$. Downhill: $X^{2}=15.823, d f=5, P=0.007$ ). At $0^{\circ}$, the average transport rate was 0.000170979 grams per second, 0.000157 grams per second for downhill gradients and 0.000131 grams per second for uphill gradients. 


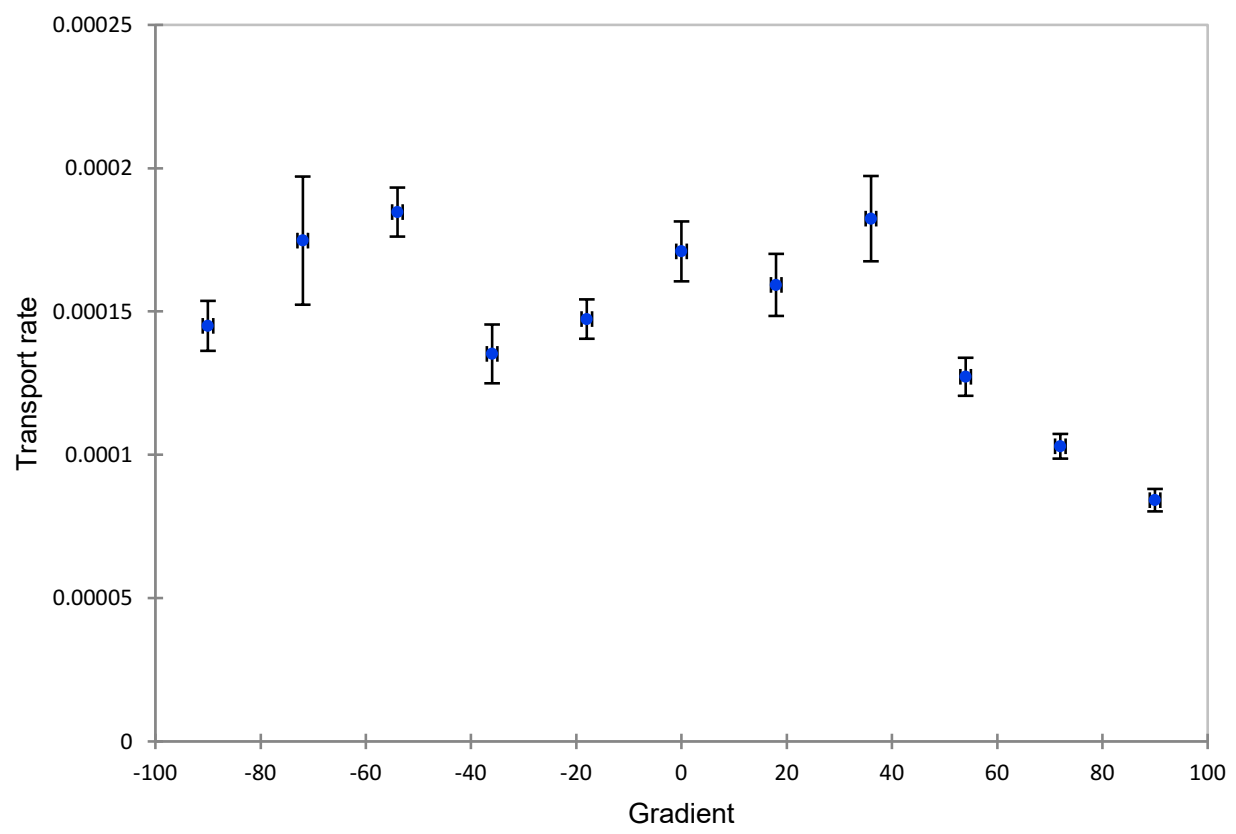

Figure 5: Mean average transport rate for each gradient tested. The error bars display the standard error of the mean.

\subsection{How do speed, loading ratio and trail gradient interact?}

Ant speed was significantly affected by loading ratio (Kruskal-Wallis test: $X^{2}=108.766$, $d f=7, P 0.001$ ), with higher loading ratios resulting in lower speeds. Kruskal-Wallis tests were conducted on each colony individually to see if the relationship between speed and loading ratio was caused by a colony level effect, but individually all of the three colonies showed a significant effect of gradient on speed (Colony A: $X^{2}=85.258$, $d f=6, P$ 0.001. Colony $B: X^{2}=79.625, d f=6, P 0.001$. Colony C: $X^{2}=17.463, d f=4$, P0.002).

Ant speed was significantly affected by gradient $\left(X^{2}=277.758, \mathrm{df}=10, \mathrm{P} 0.001\right)$ and noticeably decreased when travelling uphill (see figure 6). Downhill speeds were also slower than when on a flat trail, though the slowing effect induced by the gradient was not as great and rose sharply at -54 and -90 . The clear need to treat the uphill and downhill gradients separately led to further tests on the separated data (Uphill: $X^{2}=$ 268.447, $d f=5, P$ 0.001. Downhill: $\left.X^{2}=34.482, d f=5, P 0.001\right)$. To test the strength of 
the correlation between gradient and speed, regression analyses were performed on separated uphill and downhill data. There was a significant relationship between ant travel speed and gradient for uphill but not for downhill (Uphill: $F_{1,813}=340.480, P$ $<0.001, Y=-9.58 E-005 x+0.020$. Downhill: $\left.F_{1,791}=2.444, P 0.118\right)$. Average speed at $0^{\circ}$ was 0.0187 meters per second, 0.0161 meters per second when transporting loads downhill and 0.0149 meters per second when travelling uphill.

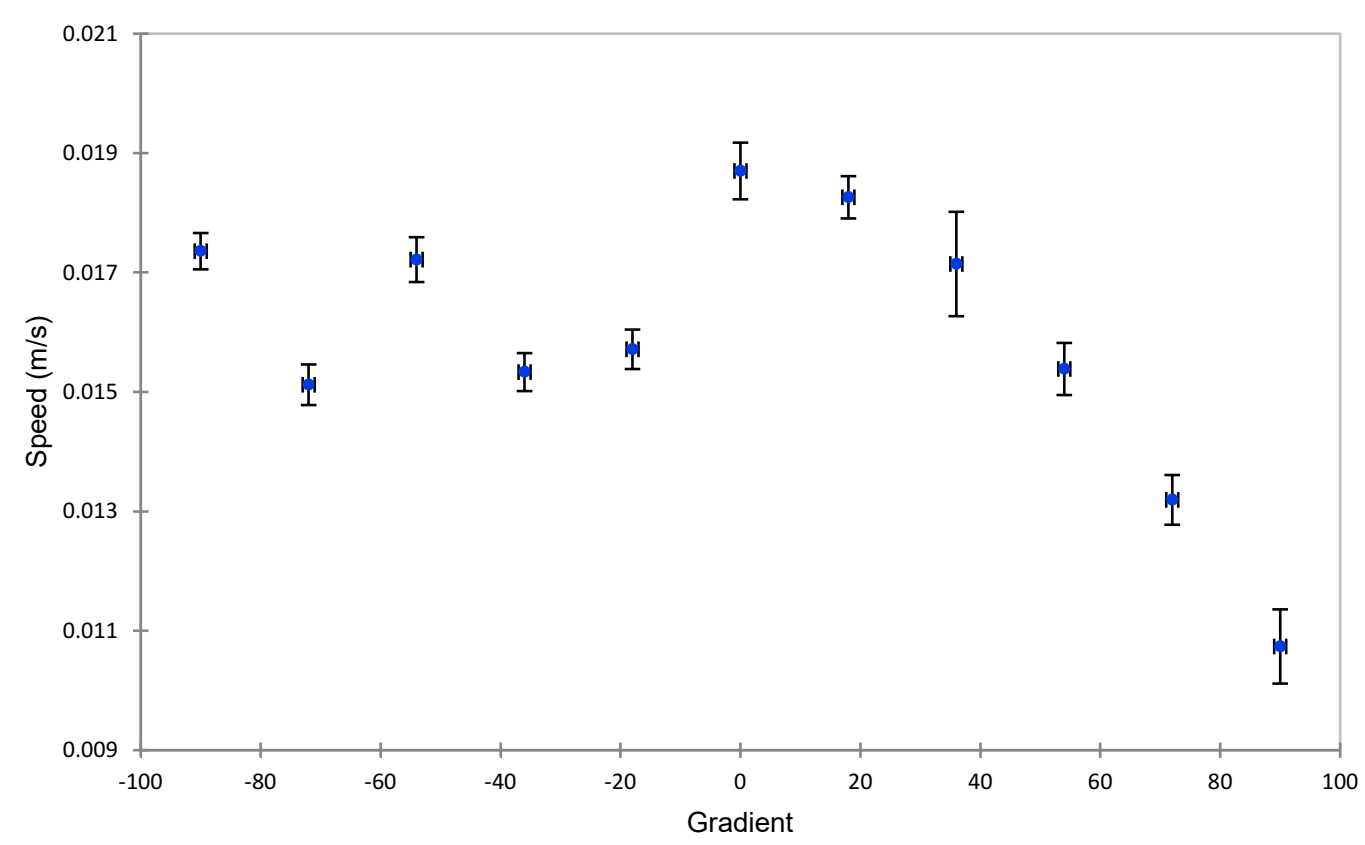

Figure 6: Mean average speed for each gradient tested. The error bars display the standard error of the mean. 


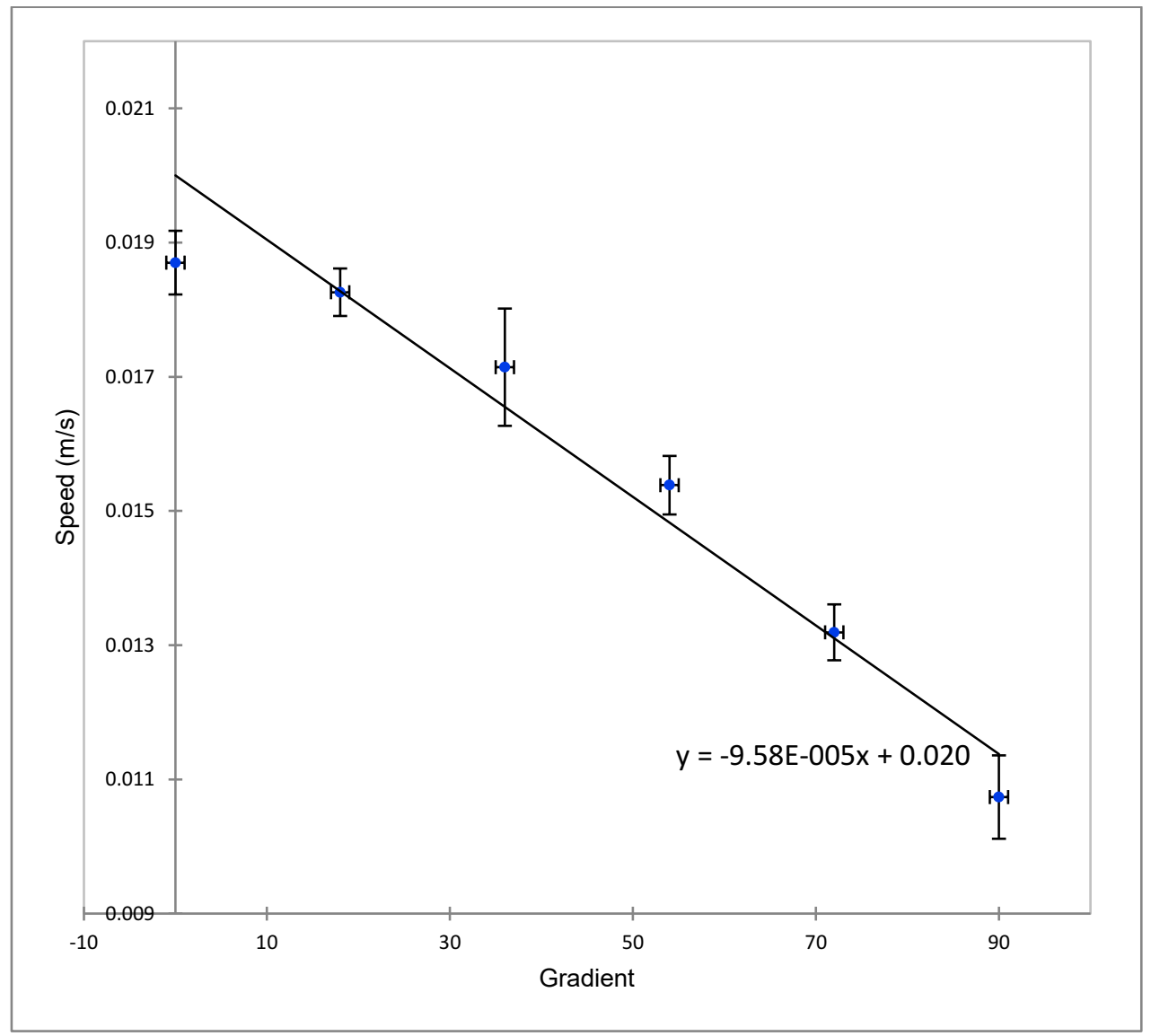

Figure 7: Ant speed vs uphill gradients, with regression line and equation. Error bars are the standard error of the mean.

Loading ratio was significantly affected by the gradient across the angles tested and as the different angles did not have similar variance, Kruskal-Wallis tests were used once again $\left(X^{2}=44.440, d f=10, P<0.001\right)$. The data were further analysed by once again splitting the data into uphill and downhill, only downhill gradients showed significant difference (Downhill: $X^{2}=21.927, d f=5, P 0.001$. Uphill: $X^{2}=7.637$, $d f=5, P 0.177$ ). Loading ratios while travelling uphill are noticably lower than those travelling downhill, though when travelling vertically downwards loading ratio drops sharply (see figure 8). Regression analysis showed no stastically significant relationship on either uphill $\left(F_{1,825}\right.$ $=0.925, \mathrm{P} 0.324)$ or downhill $\left(\mathrm{F}_{1,804}=0.441, \mathrm{P} 0.507\right)$. Loading ratio for $0^{\circ}$ averaged 2.6331, was higher for downhill gradients at a mean average of 2.8279 and lower for uphill gradients with an average of 2.6229 . 


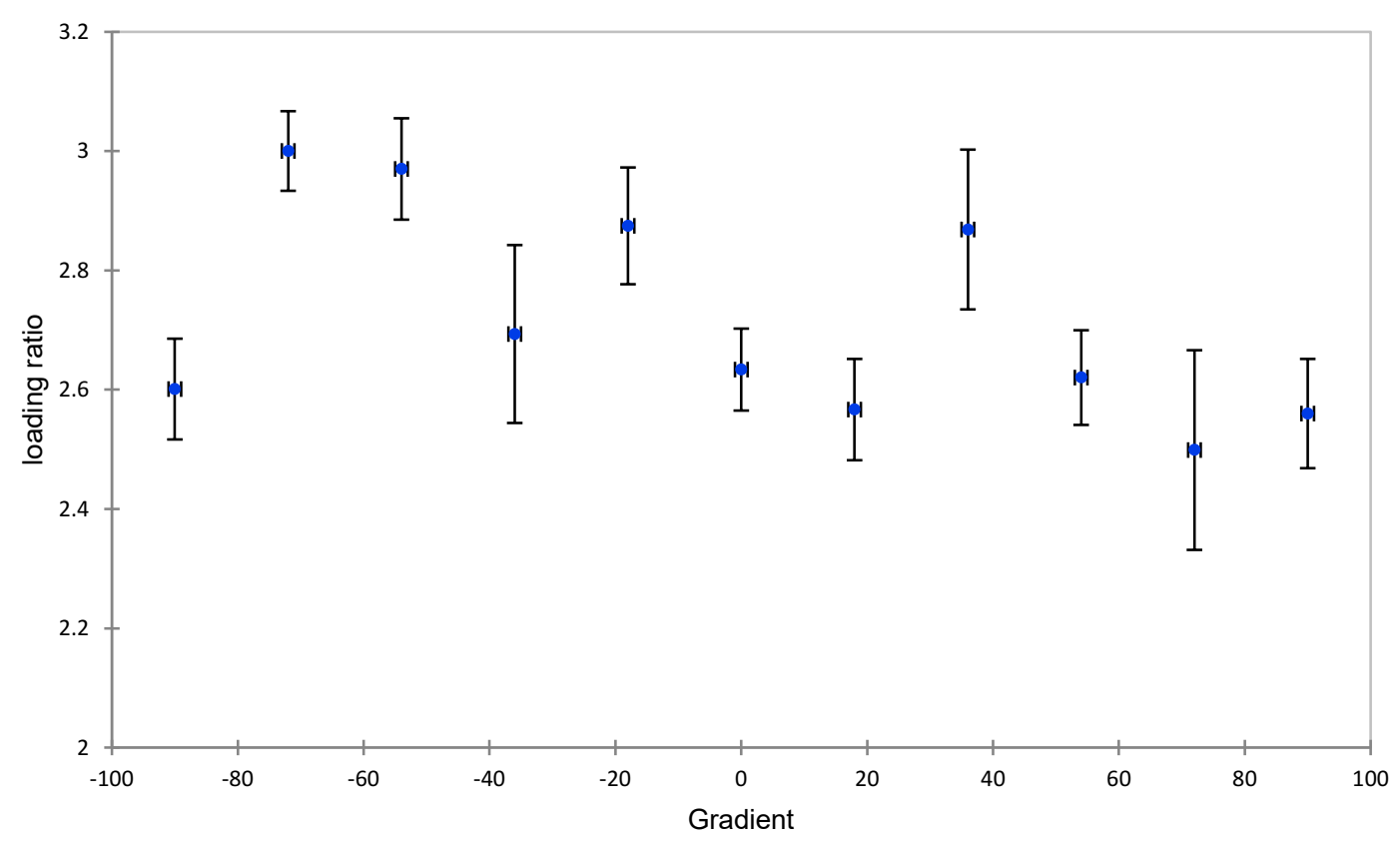

Figure 8: Mean loading ratios against gradient. Error bars show standard error of the mean.

\subsection{Does the trail gradient affect leaf size and leaf mass?}

Kruskal-Wallis tests were again used to look for a difference caused by trail gradient in both the size (measured by area in $\mathrm{cm}^{2}$ ) and weight ( $\mathrm{g}$ ) of the leaf fragments cut and showed a highly significant difference for both size $\left(X^{2}=71.11, d f=10, P<0.001\right)$ and weight $\left(X^{2}=71.114, d f=10, P<0.001\right)$. The greatest masses (mean average: $0.0123 \mathrm{~g}$ ) were cut when travelling downhill at a $-72^{\circ}$ gradient and the lowest when travelling uphill at the same gradient (mean average: $0.0084 \mathrm{~g}$ ). The size of the leaf fragments did not match up to the weights and had no clearly discernible pattern, suggesting the ants regard weight as the far more important of these two factors. Average leaf mass at $0^{\circ}$ was $0.0095 \mathrm{~g}$, increased when travelling downhill to an average of $0.0105 \mathrm{~g}$ and decreased when travelling uphill to an average of $0.0092 \mathrm{~g}$. Leaf area averaged 43.27 $\mathrm{mm}^{2}$ over all and similarly to leaf mass, was higher when travelling downhill $\left(45.59 \mathrm{~mm}^{2}\right)$ and lower when travelling uphill $\left(40.30 \mathrm{~mm}^{2}\right)$. 

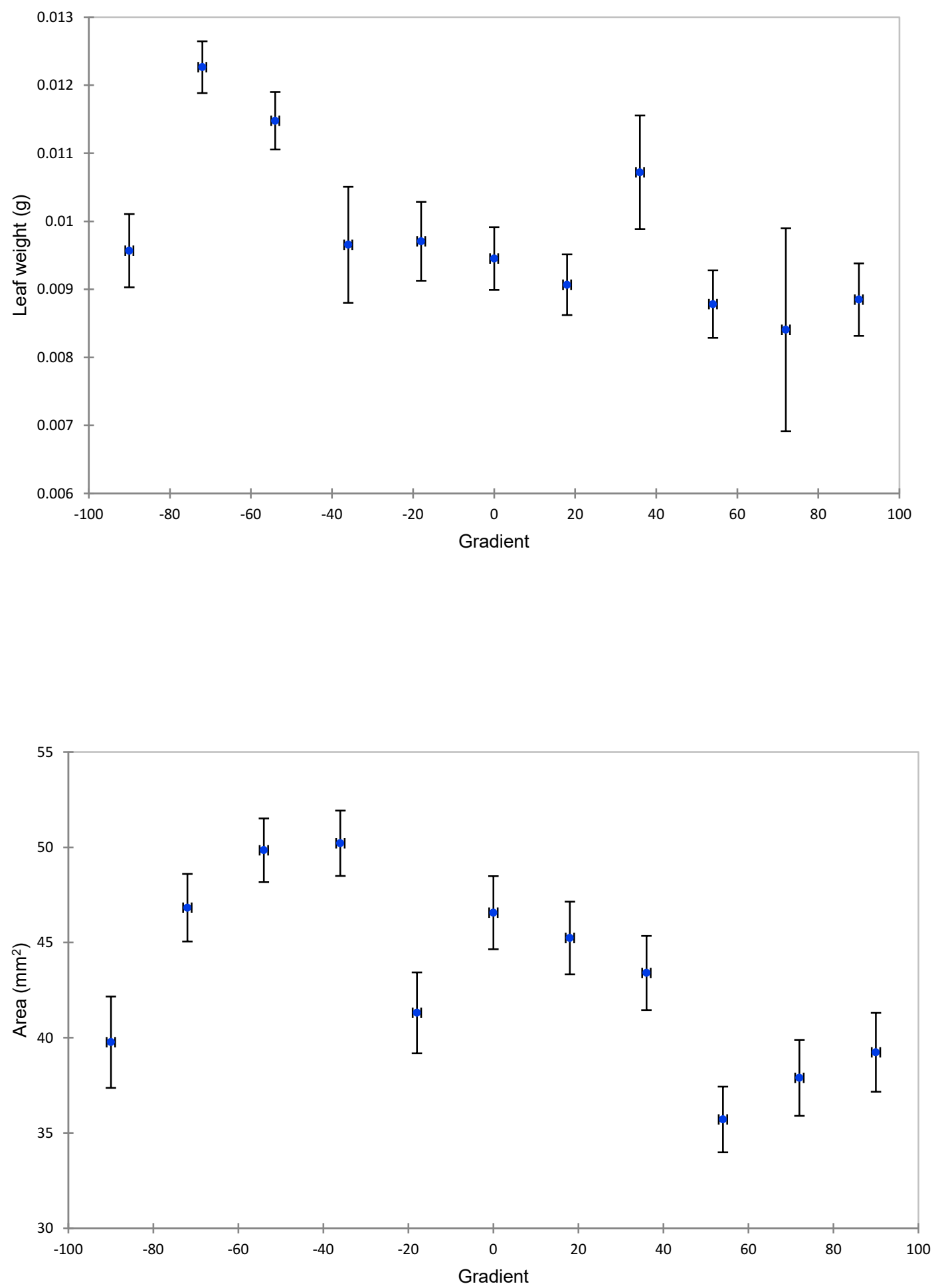

Figure 10: Mean average leaf areas at each gradient. The error bars show the standard error of the mean. 
Kruskal-Wallis tests were conducted on both mass and size by separated uphill and downhill gradients. While downhill gradients mirrored the tests on the overall data (Leaf mass: $X^{2}=18.906, d f=5, P 0.002$. Leaf area: $X^{2}=31.357, d f=5, P<0.001$ ), the uphill gradient tests revealed no significant difference in leaf mass $\left(X^{2}=9.629, d f=5, P\right.$ $0.086)$ but there was a significant difference in leaf size $\left(X^{2}=25.853, d f=5, P<0.001\right)$.

\subsection{What effect does trail gradient have on how the ants adjust their head and body} angles?

Head angles and body angles tested against a horizontal plane (gravity) were highly significant (Head vs gravity: $X^{2}=1236.909, d f=10, P<0.001$. Body vs gravity: $X^{2}=$ $1259.915, \mathrm{df}=10, \mathrm{P}<0.001)$. When these were mathematically adjusted to measure against the trail (by taking the angle between the head/body and a horizontal plane and adding or subtracting the angle of the track as appropriate), they were also highly significant (head vs trail: $X^{2}=594.227, d f=10, P<0.001$. Body vs trail: $X^{2}=230.915, d f$ $=10, \mathrm{P}<0.001)$, confirming that the ants do indeed adjust the angle at which they hold their heads, as well as their body in response to a trail gradient.

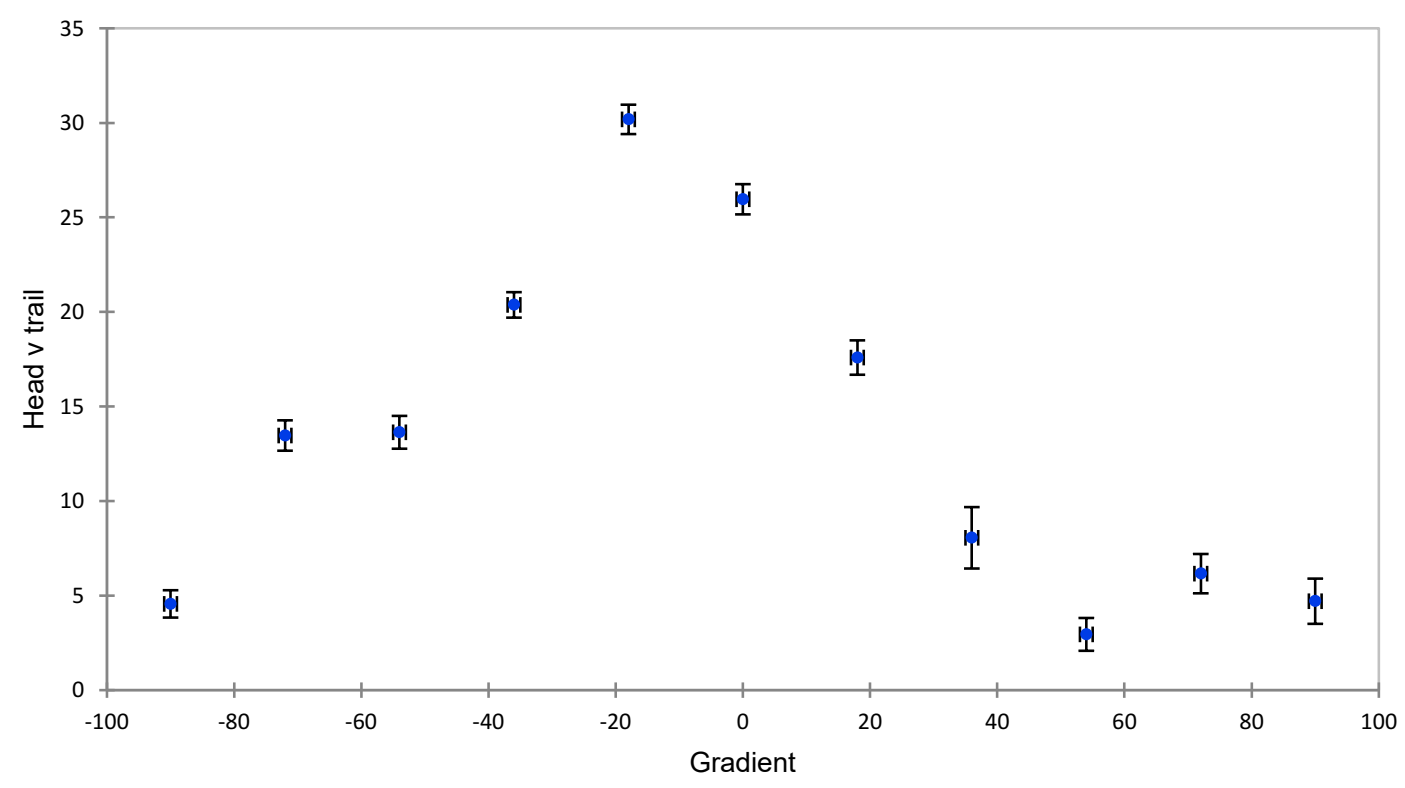

Figure 11: Mean average head angles, relative to the trail. The error bars show the standard error of the mean. 
The most extreme differences between head and trail were seen at a $-18^{\circ}$ decline (mean average: $30.1828^{\circ}$ ), though downhill gradients saw greater differences than the uphill equivalent, with the exception of travelling vertically downwards. Head angles when compared to the trail averaged $25.959^{\circ}$ at $0^{\circ}$, but across downhill gradients were lower at an average of $16.443^{\circ}$ and lower still across uphill gradients at $7.891^{\circ}$. Body angles were lower across all gradients, with the average at $0^{\circ}$ being $22.907^{\circ}, 14.515^{\circ}$ when travelling downhill and $14.416^{\circ}$ when travelling uphill. They remained similar at all gradients though some notable exceptions to this rule exist at $+18^{\circ}$ (mean average: $\left.8.051^{\circ}\right),-18^{\circ}$ (mean average: $19.966^{\circ}$ ) and $-90^{\circ}$ (mean average: $4.445^{\circ}$ ).

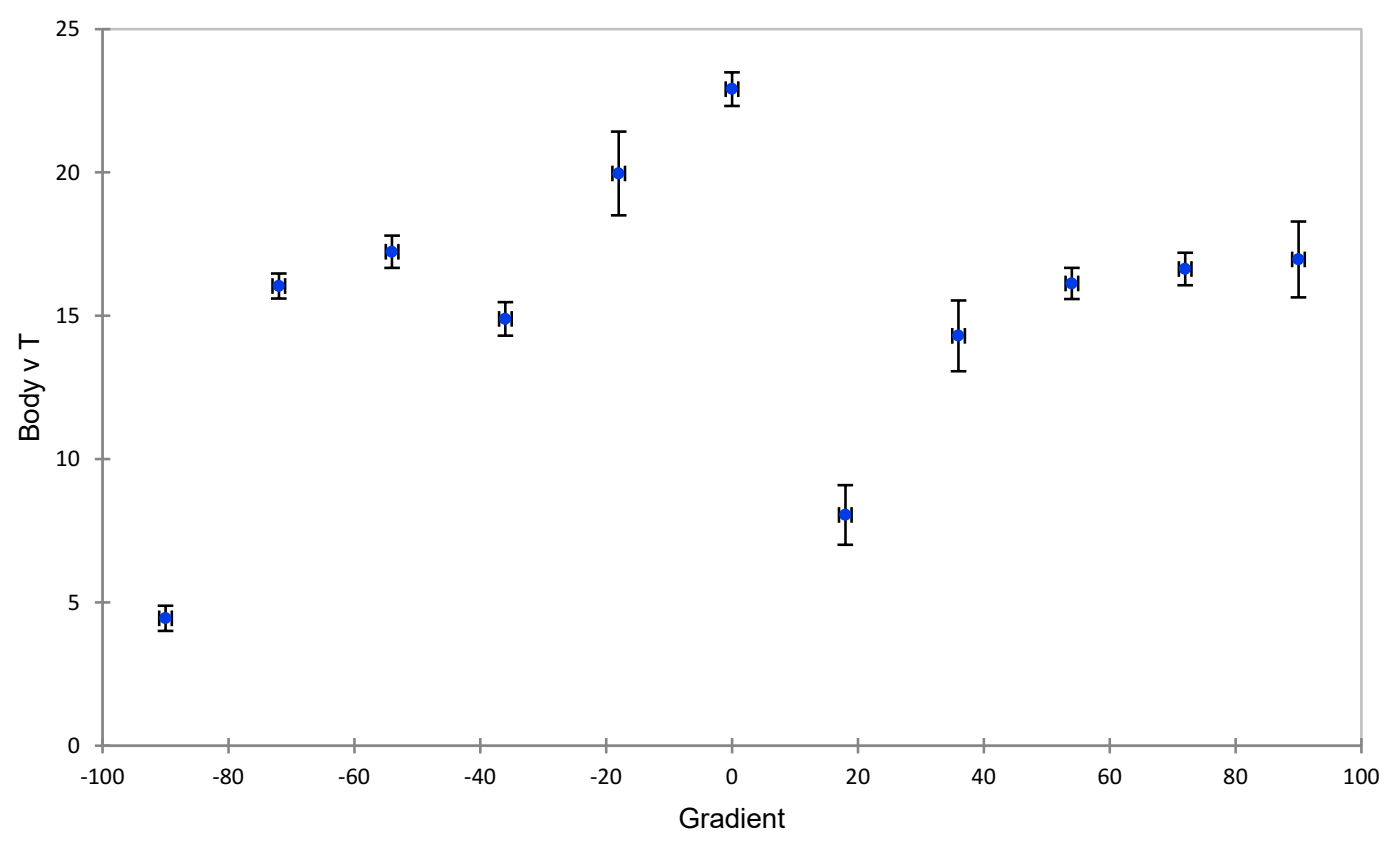

Figure 12: Mean average body angles relative to the trail. The error bars show the standard error of the mean.

At smaller gradients of -18 and +18 degrees, the adjustments made to body angle were more extreme than the rest of the data. Also worthy of note is the extremely low modification when travelling vertically downwards compared to that of travelling vertically upwards. The greatest adjustments on average were on a horizontal trail.

When mathematically calculating the difference between the ant's body and head (i.e. The angle at which the neck joint alters the angle of the head), this was also significantly different $\left(X^{2}=427.450, d f=10, P<0.001\right)$. The average adjustment the neck at $0^{\circ}$ was $3.051^{\circ}$ (indicating they adjusted their heads backwards, looking 
upwards). For downhill gradients, the mean average adjustment was $-0.793^{\circ}$ and when travelling uphill, the mean average was $-9.145^{\circ}$.

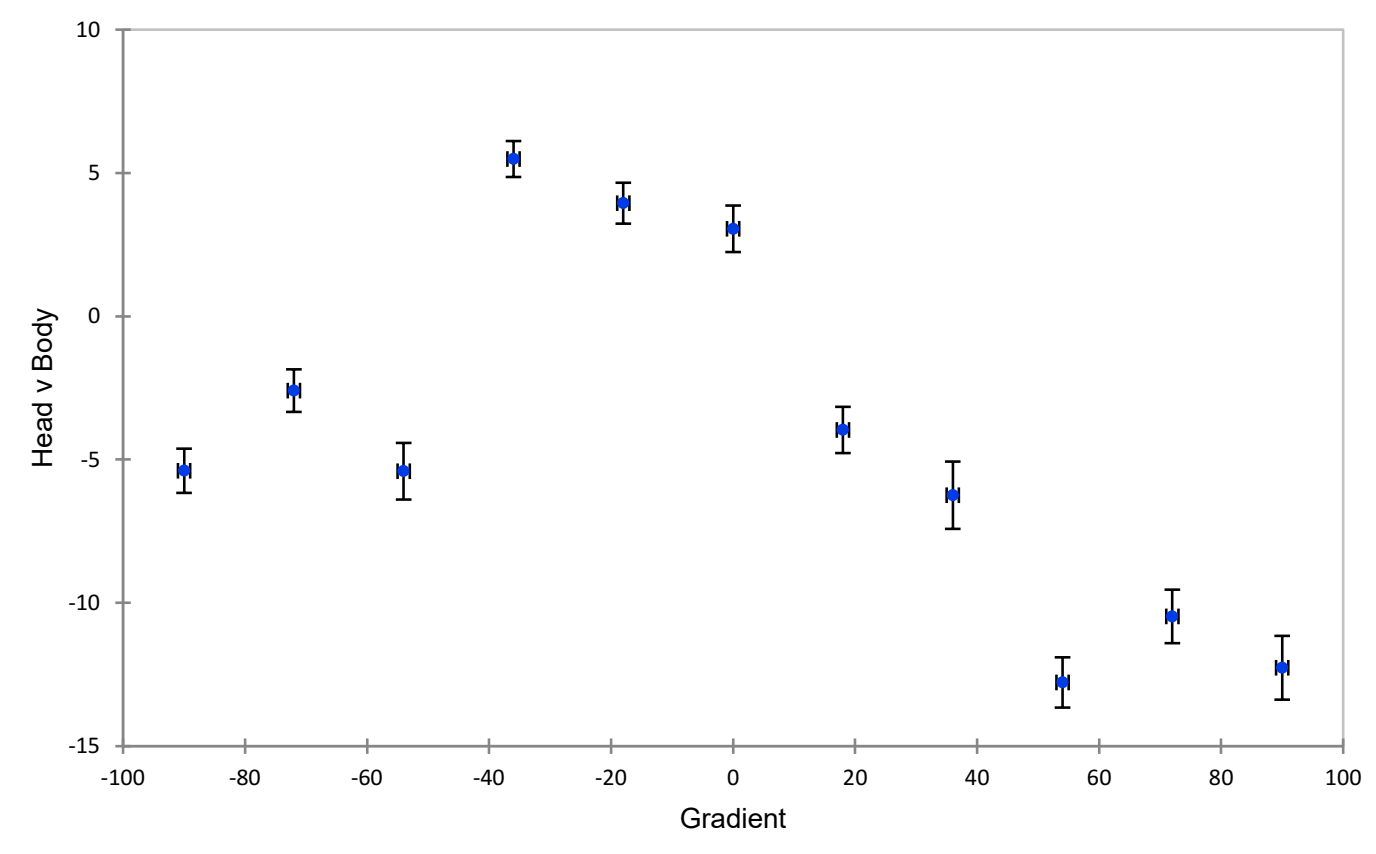

Figure 13: Mean average adjustments made at the neck at each gradient. The error bars show the standard error of the mean.

When carrying the load uphill, the ants leaned their heads forward and this was also seen at the more extreme downhill gradients, though to a lesser extent. At 0 degrees and declines of -18 and -36 degrees, the ants lifted their heads, shifting the weight of their load further backwards, though such adjustments were smaller than the more extreme uphill adjustments.

\subsection{Does gradient affect which ants decide to cut?}

To determine if the gradient was a factor in which ants cut at the feeding site, a Kruskal-Wallis test was performed and found that it did indeed have an impact $\left(\mathrm{X}^{2}=\right.$ 19.020, $\mathrm{df}=10, \mathrm{P} 0.040$ ), with larger ants tending to cut at more extreme gradients (Average ant mass at $0^{\circ}: 0.0058 \mathrm{~g}$, average ant mass at $-90^{\circ}: 0.0063 \mathrm{~g}$ ). Subsequently, the data were divided into positive and negative gradients and only downhill gradients were found to have a significant effect on the size of ants that cut leaves (uphill: $X^{2}=$ 3.231, $\mathrm{df}=5$, P 0.664. Downhill: $X^{2}=14.270, \mathrm{df}=5, \mathrm{P} 0.014$ ), with larger ants cutting when having to carry leaves downhill, with the exception of $-18^{\circ}$. Average ant weight 
at $0^{\circ}$ was $0.005843 \mathrm{~g}$, which increased to $0.005919 \mathrm{~g}$ when travelling downhill and decreased when travelling uphill to $0.005843 \mathrm{~g}$.

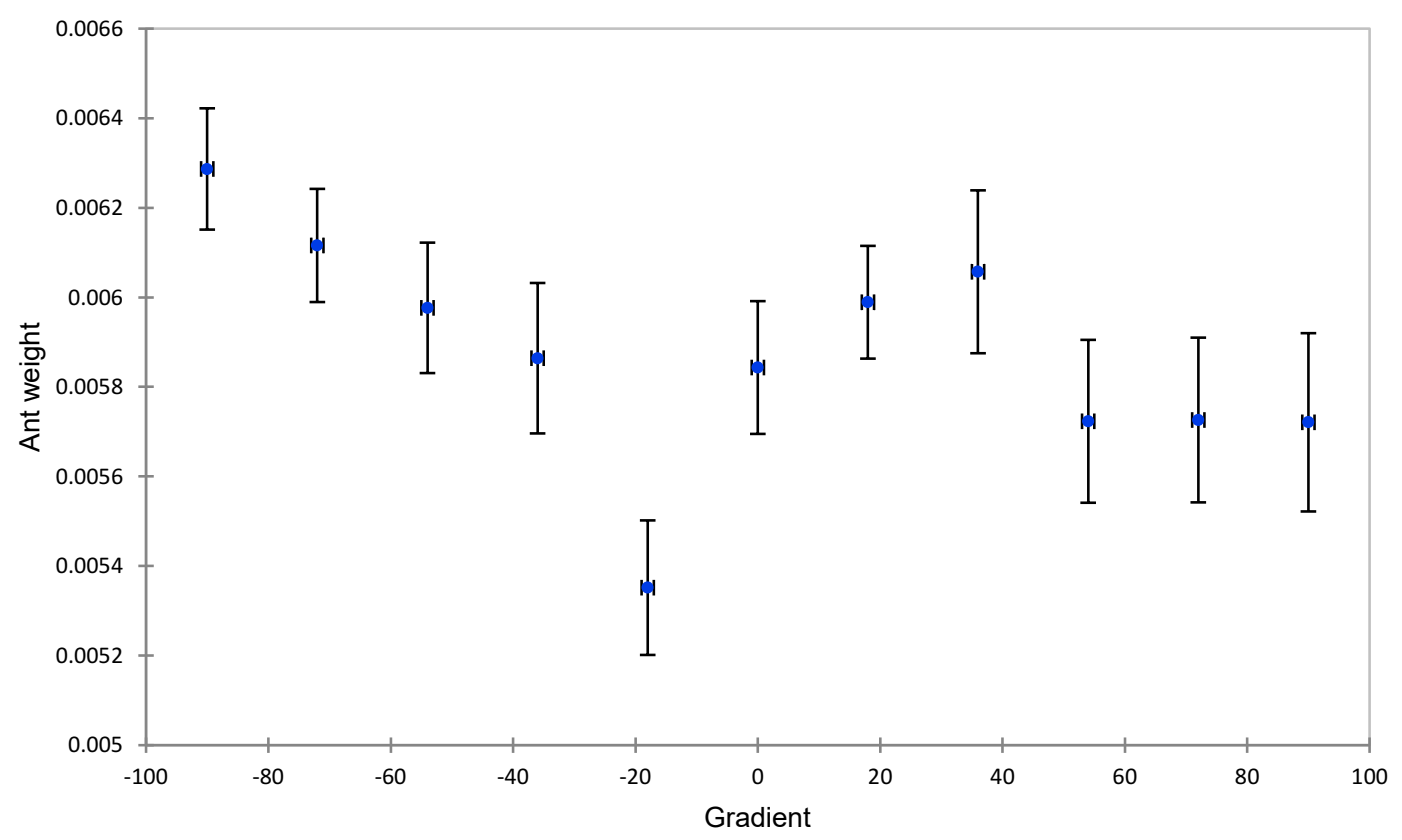

Figure 14: Mean average ant mass at each gradient tested. The error bars show the standard error of the mean. 


\subsection{Non-gradient related investigations}

The nature of this experiment gave opportunity to examine certain aspects of foraging behaviour and biomechanics that were not directly related to gradient. However, in each case gradient may have been a confounding variable and it seemed prudent to conduct individual tests on each gradient separately. In this way, it was possible to obtain a more complete picture of how these factors changed with gradient, as well as preventing other gradients from conflating the results. As the tests done were universally Spearman's Rho tests with 11 groups, the familywise error rate was controlled by using a confidence level of 0.0045 , rounded to 0.005 .

\subsection{Do larger ants elect to cut larger leaves?}

To determine if larger ants cut larger leaf fragments, Spearman's rho tests were conducted to determine a correlation between ant weight, leaf weight and leaf area. Across all gradients tested, larger ants tended to cut and collect larger leaf fragments. The same was true in regard to leaf size, except in the cases of $-90^{\circ},-18^{\circ}$ and $36^{\circ}$.

\begin{tabular}{l|llllll} 
& $\mathrm{r}$ & $\mathrm{N}$ & $\mathrm{P}$ & $\mathrm{r}$ & $\mathrm{N}$ & $\mathrm{P}$ \\
\hline$-90^{\circ}$ & 0.248 & 120 & 0.006 & 0.087 & 120 & 0.343 \\
$-72^{\circ}$ & 0.383 & 139 & $<0.001$ & 0.200 & 139 & 0.018 \\
$-54^{\circ}$ & 0.456 & 149 & $<0.001$ & 0.354 & 149 & $<0.001$ \\
$-36^{\circ}$ & 0.393 & 117 & $<0.001$ & 0.312 & 117 & 0.001 \\
$-18^{\circ}$ & 0.198 & 147 & 0.016 & 0.132 & 147 & 0.111 \\
0 & 0.386 & 134 & $<0.001$ & 0.311 & 134 & $<0.001$ \\
18 & 0.274 & 146 & 0.001 & 0.292 & 146 & $<0.001$ \\
36 & 0.215 & 142 & 0.010 & 0.157 & 142 & 0.61 \\
54 & 0.251 & 138 & 0.003 & 0.280 & 138 & 0.001
\end{tabular}




\begin{tabular}{l|llllll}
72 & 0.248 & 138 & 0.003 & 0.350 & 138 & $<0.001$ \\
90 & 0.308 & 129 & $<0.001$ & 0.360 & 129 & $<0.001$
\end{tabular}

\subsection{Do larger ants cut from denser leaves?}

To determine if larger ants cut from denser leaves, Spearman's rho tests were conducted and found there was a significant positive correlation between ant size and density across most downhill gradients (excepting $-18^{\circ}$ ) and $0^{\circ}$, but not across uphill gradients, with the exception of $90^{\circ}$ (vertically upwards). The average leaf density differed only slightly across all gradients tested, being $0.000204 \mathrm{~g} / \mathrm{mm}^{2}$ at $0^{\circ}$, $0.0002329 \mathrm{~g} / \mathrm{mm}^{2}$ for downhill gradients and $0.0002422 \mathrm{~g} / \mathrm{mm}^{2}$ when travelling uphill.

\begin{tabular}{l|lll} 
& $\mathrm{r}$ & $\mathrm{N}$ & $\mathrm{P}$ \\
\hline$-90^{\circ}$ & 0.340 & 120 & $<0.001$ \\
$-72^{\circ}$ & 0.348 & 139 & $<0.001$ \\
$-54^{\circ}$ & 0.421 & 148 & $<0.001$ \\
$-36^{\circ}$ & 0.223 & 117 & 0.016 \\
$-18^{\circ}$ & 0.157 & 147 & 0.058 \\
0 & 0.199 & 134 & 0.021 \\
18 & -0.005 & 146 & 0.954 \\
36 & 0.096 & 142 & 0.255 \\
54 & -0.012 & 138 & 0.888 \\
72 & -0.143 & 138 & 0.093 \\
90 & -0.175 & 129 & 0.048
\end{tabular}




\subsection{Do larger ants walk faster, and do they have a faster transport rate?}

To determine if larger ants walk faster, Spearman's rho tests were conducted at each of the tested gradients. Larger ants should walk faster due to a longer stride length, allowing them to cover more ground in a single step but this was not the case for $-18^{\circ}$, $0^{\circ}$ and all uphill gradients with the exception of $54^{\circ}$. The same Spearman's rho tests were performed to look for a correlation between ant weight and transport rate (load weight $X$ velocity). This proved highly significant across all gradients. It appears that while larger ants do not necessarily move faster, they compensate by taking larger loads.

Figure 17: Results of the Spearman's rho tests to determine if ant weight correlates with movement speed (left) and transport rate (right)

\begin{tabular}{l|llllll} 
& $\mathrm{r}$ & $\mathrm{N}$ & $\mathrm{P}$ & $\mathrm{r}$ & $\mathrm{N}$ & $\mathrm{P}$ \\
\hline$-90^{\circ}$ & 0.241 & 120 & 0.10 & 0.403 & 120 & $<0.001$ \\
$-72^{\circ}$ & 0.258 & 139 & 0.002 & 0.596 & 139 & $<0.001$ \\
$-54^{\circ}$ & 0.226 & 148 & 0.006 & 0.537 & 148 & $<0.001$ \\
$-36^{\circ}$ & 0.355 & 117 & $<0.001$ & 0.431 & 117 & $<0.001$ \\
$-18^{\circ}$ & 0.158 & 147 & 0.056 & 0.249 & 147 & 0.002 \\
0 & 0.133 & 129 & 0.133 & 0.311 & 129 & $<0.001$ \\
18 & 0.089 & 143 & 0.290 & 0.273 & 143 & 0.001 \\
36 & 0.019 & 142 & 0.819 & 0.182 & 142 & 0.030 \\
54 & 0.246 & 136 & 0.004 & 0.365 & 136 & $<0.001$ \\
72 & 0.084 & 138 & 0.329 & 0.342 & 138 & $<0.001$ \\
90 & 0.013 & 129 & 0.886 & 0.382 & 129 & $<0.001$
\end{tabular}




\subsection{Do ants carrying larger leaf fragments slow down?}

To determine whether ants carrying large leaf fragments carried at a slower speed, Spearman's rho tests were conducted on each of the tested gradients separately. Generally, larger loads did cause the ants to slow down.

Figure 18: Results of the Spearman's rho tests to determine if leaf weight correlates with speed.

\begin{tabular}{l|lll} 
& $\mathrm{r}$ & $\mathrm{N}$ & $\mathrm{P}$ \\
\hline$-90^{\circ}$ & -0.360 & 120 & $<0.001$ \\
$-72^{\circ}$ & -0.402 & 139 & $<0.001$ \\
$-54^{\circ}$ & -0.228 & 148 & 0.005 \\
$-36^{\circ}$ & -0.105 & 117 & 0.259 \\
$-18^{\circ}$ & -0.180 & 147 & 0.030 \\
0 & 0.033 & 129 & 0.709 \\
18 & -0.164 & 143 & 0.050 \\
36 & -0.004 & 142 & 0.964 \\
54 & -0.211 & 136 & 0.014 \\
72 & -0.447 & 138 & $<0.001$ \\
90 & -0.488 & 129 & $<0.001$
\end{tabular}




\subsection{Does the angle of the ant's head or body have an effect on their speed?}

To determine how the adjustments the ants make affects their speed, Spearman's rho tests were conducted in the same way as in the previous analyses on the head angle relative to the gradient of the track, body angle relative to the gradient of the track and their head angle relative to their body.

Figure 19: Results of the Spearman's rho tests to determine if the angle of the ant's body relative to the trail (left) or head relative to the trail (right) correlates with speed.

\begin{tabular}{l|llllll} 
& $\mathrm{r}$ & $\mathrm{N}$ & $\mathrm{P}$ & $\mathrm{r}$ & $\mathrm{N}$ & $\mathrm{P}$ \\
\hline$-90^{\circ}$ & 0.207 & 98 & 0.041 & -0.092 & 98 & 0.368 \\
$-72^{\circ}$ & 0.103 & 124 & 0.253 & -0.086 & 123 & 0.343 \\
$-54^{\circ}$ & 0.046 & 116 & 0.622 & -0.192 & 122 & 0.034 \\
$-36^{\circ}$ & -0.605 & 67 & $<0.001$ & -0.359 & 67 & 0.003 \\
$-18^{\circ}$ & 0.190 & 132 & 0.029 & -0.174 & 132 & 0.46 \\
0 & -0.020 & 98 & 0.843 & 0.198 & 98 & 0.051 \\
18 & 0.070 & 142 & 0.410 & 0.104 & 141 & 0.221 \\
36 & -0.205 & 136 & 0.016 & 0.017 & 136 & 0.844 \\
54 & -0.153 & 119 & 0.096 & 0.117 & 119 & 0.205 \\
72 & 0.064 & 132 & 0.465 & -0.148 & 132 & 0.091 \\
90 & 0.083 & 117 & 0.375 & -0.330 & 117 & $<0.001$
\end{tabular}


Figure 20: Results of the Spearman's rho tests to determine if the angle of the ant's head relative to its body correlates with speed.

\begin{tabular}{l|lll} 
& $\mathrm{r}$ & $\mathrm{N}$ & $\mathrm{P}$ \\
\hline$-90^{\circ}$ & -0.092 & 98 & 0.368 \\
$-72^{\circ}$ & -0.086 & 123 & 0.343 \\
$-54^{\circ}$ & -0.192 & 122 & 0.034 \\
$-36^{\circ}$ & -0.359 & 67 & 0.003 \\
$-18^{\circ}$ & -0.174 & 132 & 0.46 \\
0 & 0.198 & 98 & 0.051 \\
18 & 0.104 & 141 & 0.221 \\
36 & 0.017 & 136 & 0.844 \\
54 & 0.117 & 119 & 0.205 \\
72 & -0.148 & 132 & 0.091 \\
90 & -0.330 & 117 & $<0.001$
\end{tabular}




\subsection{Discussion}

Initially, this study's intent was to re-examine the results of Lewis et al's experiment (2008). A number of experimental flaws (detailed earlier) were identified in their approach but despite this, gradient would seem to be an important factor in foraging dynamics.

In this study, I found a significant interaction between loading ratio and gradient, with uphill gradients resulting in a lower overall loading ratio and downhill gradients resulting in a higher loading ratio, with the highest being at steep declines of $-72^{\circ}$ and $54^{\circ}$. Larger ants also chose to cut when they had to travel downhill, which I attribute to greater forelimb strength, as the forelimbs must provide the greatest force opposing gravity. Overall transport rate decreases as gradients get steeper and grip becomes more and more important. Finally, declines of $-18^{\circ}$ differed from the overall trend of the data or induced the biggest adaptation in many of the tests conducted here, which suggests that the ants face this manner of gradient so frequently that ants with traits that enabled them to better adapt to it may have been evolutionarily selected for.

These results differ from Lewis et al's work (2008) in several respects. While they found no significant interaction between loading ratio and gradient, this study showed that there was a significant difference in loading ratios, with downhill gradients resulting in heavier ants and heavier leaf fragments. In their experiment, the highest loading ratios were found when the feeding site was directly above the nest $\left(+90^{\circ}\right)$, but here, they were found at steep declines. While both this study and theirs agree that overall transport rates decreased as the gradient gets steeper, further analysis in this study revealed this only occurs when travelling carrying loads uphill.

As for the case of $-18^{\circ}$, this may be as a result of their hygiene procedures. Foraging trails are frequently orientated away from waste dumps, which are located downhill from the nest when possible (Hart and Ratnieks, 2001). This would mean that they would often have to move uphill when travelling away from the nest and thus, carry downhill on the return journey. 
Finally, throughout gradient related examinations, I found evidence suggesting that grip was the most important factor to the ants and other factors seemed to be secondary. Speed and transport rate were sacrificed in favour of maintaining a better grip and avoiding the loss of the load.

\subsection{Disentangling decisions and biomechanical adaptations}

The primary difficulty with bridging the gap between biomechanics and decisions made by the ants is deciding which came first. Was a decision made and then the ant subsequently facilitated that decision through other adaptations? or was a biomechanical limitation encountered, which forced the ant to adapt to it?

For the ants, this question is simplified by the relative simplicity of their options. While humans may change hands, use both hands, shift some weight to the other hand or even place the load in a bag or rucksack to enable them to carry the load over their back, on their shoulders or put it in pockets, the ants only have the choice to carry it between their mandibles or to not carry at all. With that settled, their main decisions are how much weight to carry, how to adjust to that weight and what speed to travel at. However, there will always be a limiting factor, where the laws of physics take the decision out of the ant's "hands". As strong as the ants are for their size, if the load is too great, they simply cannot move it.

However, leaf cutting ants are a curious case where a central place forager tends to collect below its maximum capacity. On average, Atta cephalotes tends to cut between one quarter and one third below a calculated size that would optimise individual delivery rate or optimise for energy efficiency (Burd, 2000), when most central place foragers tend to attempt to maximise these factors, such as beavers cutting wood for their dams (Basey et al., 1988). Numerous hypotheses have been presented to explain this, such as the theory that the ants optimise from foraging site to fungus, rather than merely from foraging site to the nest, as the leaves must be cleaned, shredded and then placed into the fungal garden for there to be any point in gathering them, meaning that cutting at the foraging site and subsequent transport is only part of the 
story (Burd and Howard, 2005). Considering this, alongside evidence from other species, such as an Oecophylla longinoda specimen holding up a baby bird that was approximately 1200 times its own weight (Wojtusiak et al., 1995) and the fact that ants are capable of lifting many times their own body weight (Wetterer, 1994), it seems reasonable to assume that pure weight was not limiting factor, as the average load weight was a mere 1.675 times the average ant weight across all angles.

This would lead to the conclusion that all of the adaptations are as a result of choices, rather than limitations, there is another factor to consider and that is one of balance. In this regard, the ants are already disadvantaged as their only means to grip the load (the mandibles) are at the very front of their body and as a result, leaf cutting ants of all genera are commonly seen with their loads tilted backwards in order to keep the centre of gravity between their legs and keep them balanced (Moll et al., 2010). This is complicated when a gradient is introduced and could potentially become a destabilising effect and that point, it could well become a limiting factor and as such, balance becomes a critical factor in determining what is limited by biomechanics and what is limited by the ant's decisions. With this in mind, the various factors examined in the results section will be divided two sections. The first will be primary decisions made by the ants, while the second will be behaviours which are forced on the ants either by the biomechanics involved or as a result of needing to adapt to the primary decisions made at the foraging site. Where appropriate, grip and balance will be used as a lens to examine the potential causes of the observed behaviour. 


\subsection{Primary Choices}

\subsubsection{How does trail gradient affect the size of the ants who choose to cut?}

Before any decision is made about what sized leaf to cut or how to carry it, a foraging ant must first decide whether to actually cut a leaf fragment. This poses the ant an interesting problem. They have just walked along a trail and now, assuming they have the memory capacity to do so, they must consider the challenges that the trail posed in reverse, as where they walked uphill, they must then carry that load downhill and vice versa. Humans are vulnerable to the "sunk cost" fallacy, in which past effort (in this case, travelling to the foraging site) motivates further effort towards a goal, when it may be better to simply abandon the task (Arkes and Ayton, 1999). However, only a small percentage of the ants which travelled to the feeding site in this study cut or carried leaf fragments back, indicating that the ants like many lower animals (Arkes and Ayton, 1999) do not fall prey to this fallacy.

It turns out that gradient does have a significant impact on whether they cut or not, but not as might be expected. While we might assume that carrying the leaves uphill might be more difficult based on our own experiences, the opposite is true. Ant size increased at $18^{\circ}$ and $36^{\circ}$ but remained relatively constant at $54^{\circ}, 72^{\circ}$ and $90^{\circ}$, with the mean average ant sizes for each angle being within just 0.000003 grams of each other (approximately $0.05 \%$ of average ant mass). In contrast, with the exception of a sharp drop at $-18^{\circ}$, downhill angles showed a steady increase in ant weight (see figure 8).

While gradients lie on a linear scale, the effect of gradient on the ants does not scale linearly. An ant travelling on a level plane $\left(0^{\circ}\right)$ will experience gravity pulling directly downwards towards the trail but an ant travelling vertically upwards $\left(90^{\circ}\right)$ will experience gravity pulling them and the load directly backwards towards their abdomen, threatening to tip them backwards. The inverse is true when carrying a load vertically downwards $\left(-90^{\circ}\right)$ as gravity still pulls downwards, but this time, that threatens to tip them forwards. This effect is multiplied if the ant loses its footing with one or more feet, which would increase the strain placed on the remaining attached feet and possibly lead to the ant losing its grip entirely. Therefore, the morphology of 
the ant's feet and how this changes as worker size increases might provide an answer as to why larger ants might cut when travelling uphill, but not when travelling downhill.

Atta cephalotes has two main structures on their feet: The claws and the tarsal pads (Stark et al., 2019). The claws are curved and extend away from the tarsal pad located in the centre of each foot, giving each leg three points of contact with the ground when walking on a flat surface and hook into asperities on vertical surfaces (Pattrick et al., 2018). The size of Atta cephalotes claw tip diameters do not increase as quickly in ants of varying sizes and worker castes (even majors), as they do in other insects, according to an investigation by Pattrick et al (2018), possibly because the asperities which the ant's claws would have to grip to would be the same regardless of the size of the ant. The study investigated grip strength by exposing the ants (and other insects) to varying degrees of roughness and centrifugal force (Pattrick et al., 2018). They found that while larger $A$. cephalotes specimens tended to perform worse on rougher surfaces, there was no evidence that larger individuals were any more likely to lose their grip than the smaller nestmates (Pattrick et al., 2018). However, they did comment that the claws of larger $A$. cephalotes specimens would suffer increased stress and be at higher risk of breaking.

The tarsal pads are smooth, lubricated areas on the ant's feet that can be used to create an adhesive force through surface tension and fluid viscosity under perpendicular loadings and through viscosity and friction under parallel loadings (Stark et al., 2019). This means that while travelling on a flat surface ( $0^{\circ}$ in this study), surface tension is a factor, but while travelling vertically up or down, friction replaces it. Presumably, these two factors would rise and diminish in importance and impact across the intermediate angles. Non-arboreal ants either lack these pads or have much smaller pads than arboreal ants like Atta cephalotes so their potential importance in gripping onto surfaces with a rugosity typical of tree barks is hard to ignore (Stark et al., 2019). 
Examinations of the tarsal pads found that the size of these tarsal pads did not scale proportionately with ant size (Stark et al., 2019). However, this study was focused on the roles that the ants played (i.e. majors, leaf carrying workers and "riders", who were smaller than leaf-carrying workers who climb leaves being carried by other workers to deter predation), not specifically on the size of individual workers. This resulted in proportionally less adhesion against sheering forces for the majors compared to regular workers and although riders had the greatest proportional tarsal pad size, carrying workers had the greatest adhesive strength, suggesting that other factors beyond tarsal pad size are at play when determining their grip strength, against shearing forces (Stark et al., 2019). However, in terms of raw adhesive strength, the majors produced the greatest adhesive strength. If this were to be mirrored across all worker castes, then this would explain why larger ants cut at higher gradients as grip would be more important on vertical or steep gradients.

However, this does not explain why bigger ants only cut when travelling downhill, because if grip strength were the only factor under consideration, it should have been mirrored when transporting uphill as well. For this, we must consider that the hind pair of legs in Atta are longer and thicker than the fore and mid legs (Lopes, 2013). As strength usually increases when muscle size increases, it is reasonable to assume that the hind legs are stronger than the fore legs. In an investigation into how the weaver Oecophylla smaragdina utilises different parts of its tarsus (including a pad of tarsal hairs) travelling on a flat plane, upside down and vertically upwards, Endlein and Federle (2015) found that the hind legs produced a greater proportion of the grip than the other two pairs of legs and that different parts of the tarsus were used depending on whether or not the legs were above or below the ant's centre of mass (Endlein and Federle, 2015). No specific research examining these tarsal hairs mentions $A$. cephalotes as having them, though as they have been found in old world (Hölldobler and Wilson, 1990) and new world ants (Endlein and Federle, 2015) and Endlein and Federle describe "ants" in general as having them, I am inclined to believe that $A$. cephalotes does indeed possess these pads of tarsal hairs. Regardless, Atta will be 
subject to the same physical mechanics and this would mean that when travelling downwards, the fore legs would have to produce the most force to counteract gravity, rather than the much larger hind legs, which may explain why larger workers chose to cut when they would have to travel downhill to reach the nest. With their greater overall strength, the weaker front legs would be more able to counteract gravity than smaller nestmates, which would result in faster and more efficient transport.

\subsubsection{Does the gradient affect the size of the leaf fragments which the ants choose to cut?}

Now that an ant has decided that the leaves are worth bringing back to the nest, it must cut a fragment from the whole leaf in order to transport it efficiently and ultimately, bring it into the nest through the small opening, for further processing. Apart from the physical limitations of actually getting it into the nest, previous research has shown that the majority of processing actually occurs inside the nest and is accelerated with smaller fragments (Burd and Howard, 2005). Increased processing speed has been proposed as an explanation for why $A$. cephalotes consistently cuts leaf fragments smaller than would optimise transport rates (Burd and Howard, 2005). Just as each ant individually decides whether to cut or not, they must also decide what size fragment to cut. If the fragment is too small, then there is a risk that the resource brought into the nest will not be worth the energy expended. On the other hand, if the fragment is too large, and the ant struggles, there is an increased risk of losing the leaf fragment or causing an obstruction on the trail and slowing colony wide resource collection rate. Even if the ant is only slowed a little when multiplied by the hundreds of thousands of ants which could be gathering, this can add up to a significant cost in energy is expenditure and reduction in transport rate. As a result, most ants (87\%) choose fragments between 1.5 and 6 times their own mass (Wetterer, 1994) and while the average load mass this experiment was 1.675 times the average ant mass, only $53.36 \%$ of ants in this experiment fell within that range, though at each angle sampled, all mean averages fell within that range. 
In 2013, an investigation into the effect of gradient on the Acromyrmex octispinosus (a relatively mono-morphic leaf cutter ant species which demonstrates distinctly different behaviour to Atta cephalotes) by Norton et al. found that when travelling downwards to the nest, the ants cut heavier loads (Norton et al, 2014). They attributed this to the slower speeds observed when the ants carried loads vertically upwards and the assumption that unladen ants would also move slower (Norton et al, 2014). I found a similar effect in Atta cephalotes in that the heaviest loads were when returning to the nest at $-72^{\circ}$ (See figure 9) and that the ants did indeed move slowest when carrying loads uphill. Both myself and Norton relate our work back to Lewis et al (2008) who neglected to report on raw load mass, focusing on loading ratio instead (Lewis et al, 2008).

A simple explanation might be that because of the increased energetic costs of moving uphill, the ants might not cut large loads if they have walked downhill to a leaf source. As a large load will increase the costs of travel by more than a small load and when travelling uphill one could assume that the energy cost is greater, which would yield an even smaller return. However, work with Camponatus ants actually showed no significant increase in metabolic energy consumption per unit distance when moving vertically (Lipp, et al., 2005). As interesting as this finding is, it should be noted that Camponatus had a mean mass of $12 \mathrm{mg}$, while the mean mass of $A$. cephalotes workers in this study was 60mg, approximately 5 times the mass. Indeed, Lipp et al (2005) attributed their findings to the extremely low mass of the ants and work with larger insects (primarily cockroaches) has shown that there is a significant energy increase when moving uphill, even amongst insects weighing less than $1 \mathrm{~g}$ (Full and Tullis, 1990). It should be noted that Holt and Askew (2012) showed that unladen Acromyrmex octispinosus workers had a metabolic rate that stayed constant by the regulation of speed, even as the energy required to move up an incline increased on both inclines and declines (Holt and Askew, 2012). By adjusting speed, they ensured a constant metabolic rate which must confer some benefit on the trail (Holt and Askew, 2012), 
possibly a reduction in bottle necking due to fatigue induced slowdowns when making long journeys.

With increased energy costs, it is worth considering the limited bounty of food offered in this study. Assuming that the ants evaluate the quantity of food available in some fashion (Czaczkes et al, 2013), it is possible the ants choose to expend less of their own energy and let some of their nestmates shoulder more of the burden. If we consider that the colony has invested a certain amount of non-refundable energy through the division of food into each ant, then each individual should attempt to maximise its efficiency. However, as nestmates have already made the journey to the food source, it makes little sense to overburden themselves. The other ants in the colony must travel back to the nest anyway and depending on how much they increase their energy costs by overburdening themselves, it may cost the colony more energy than simply allowing other workers to carry some back.

This is one of the many potential trade-offs of a lab experiment as opposed to a field experiment. In exchange for being able to reliably get the data required to test a hypothesis, there is a risk of inducing behaviours which would never be seen in wild ants. As they are not in a forest and food sources are provided periodically (a necessity for any kind of lab-based husbandry) rather than being available at all times, the ants will almost certainly have adapted to this and possibly produce different behaviours than wild colonies. For this reason, a field study would be a necessity to determine the validity of these findings. A preliminary study could be fairly easily done with a colony positioned near a river, which would by necessity have to find a bridge to cross. Natural bridges could be removed and an artificial, semi-permanent created, so that ant behaviour could be recorded across it. Aside from change the gradient, the artificial bridge could be left open to the ants at all times, allowing for long term observation in the wild. 


\subsubsection{Gradient and compensation through adjustment to the head and body angles}

Head and body angle varied significantly across all angles tested and as a result, the difference between the head and body was also highly variable. In all instances of the body being adjusted, the ant raised itself up on its front legs so that body climbed to a higher (more positive) angle. As Moll et al. (2013) found, leaf cutting ants of $A$. vollenweideri lift their heads to prevent their grass fragments from touching the ground (Moll et al, 2013), presumably to avoid the costs in terms of friction, contamination with dirt and soil dwelling fungus and to avoid knocks or bumps which might cause the ant to lose its footing and grip. As $A$. cephalotes leaves are of a more irregular shape than the grass fragments cut by $A$. vollenweideri, it would make sense for them to be flexible and also use their bodies to help with this, but this was not reflected in the data. At all angles, the ants raised their heads (mean average measurements for each angle), which would indicate that they were trying to keep the leaves off the ground. Surprisingly, leaf area also did not correlate with head angle either when only ants running on the $0^{\circ}$ flat plane were considered, suggesting where the ant grips the leaf fragment may be the most important factor in avoiding bumps along the trail. However, it should also be noted that no attempt has been made to quantify what portion of the leaf is below the ant's mandibles during transit or if bumps occurred. Whether the ants carefully choose where to grip the leaf fragment or simply adapt to it once they have found a strong enough grip could be tested by providing the ants with uniform paper fragments (as is standard practice) and recording them when travelling along a trail at various gradients and rugosities.

As previously mentioned, Moll's et al's experiment in 2010 suggested that grass cutting ants use their heads to adjust the centre of mass when travelling along shallow gradients $\left(-20^{\circ}-20^{\circ}\right)$ and at similar angles (Moll et al, 2010), l observed almost identical results, finding that when travelling uphill at $18 / 20^{\circ}$, ants held their heads at a mean angle of around $30^{\circ}$ relative to the trail and at the equivalent decline they held their heads at $10-15^{\circ}$ relative to the trail. At $0^{\circ}$, ants held their heads at only a slightly lower angle than when on a $18 / 20^{\circ}$ incline, suggesting that both species of Atta have 
evolved similar mechanisms to better carry their loads at such angles, despite varying in size ( $A$. vollenweideri $-0.0058 \mathrm{~g}-0.0231 \mathrm{~g}$, A. cephalotes (this experiment) $-0.0022 \mathrm{~g}$ $-0.0128 \mathrm{~g}$ ) and load mass selection $(A$. vollenweideri $-0.0031 \mathrm{~g}-0.0534 \mathrm{~g}, A$. cephalotes (this experiment) $-0.0005 \mathrm{~g}-0.2065 \mathrm{~g}$ ) (Moll et al, 2010). While unmeasured in this experiment, it should also be noted that the leaf fragments cut by A. cephalotes in this study were, in nearly all cases, noticeably smaller in any single dimension than the $12-49 \mathrm{~mm}$ lengths recorded in A. vollenweideri (Moll et al., 2010).

I am inclined to agree with Moll et al in their conclusion that these head movements are to maintain stability and, therefore, maintain a constant rate of leaf transport without disruption or loss by maintaining the centre of mass between the tripod formed by the ant's legs at every step. This method of moving the head backwards to maintain stability works well when travelling at a small incline or decline but at more extreme angles, when gravity pulls in an entirely different direction, it becomes detrimental as it would shift the centre of mass away from the surface the ant is moving along. It would be wrong to say that at these gradients, stability is less important but rather than avoiding disruption to the trail, stability is key to maintaining grip and avoiding falling off the trail entirely or having to drop the load in order to stay adhered. Stability in this instance would mean that the ant would reliably be able to attach each leg after each step and in so doing, ensure they always maintained a good grip.

With intermediary uphill angles, the mean angle of head elevation remained fairly constant from slopes of $36^{\circ}$ and steeper, ranging from $2.96^{\circ}$ to $8.05^{\circ}$. These minor adjustments suggest that by placing load in front of them, they place their body between the leaf and the pull of gravity, acting as a physical barrier between it and the leaf fragment. In so doing, like in the vertical example, it minimises any forces from the leaf fragment which might mean the ant risks losing the leaf or falling off the trail.

It also means that if the ant loses its grip on the leaf, the leaf fragment would fall to the ground and be prevented from falling further by the ant's mandibles and head, 
which would allow the ant to drop the leaf if its own balance was threatened, with a much smaller chance of losing the load. This would mean that less load loss was incurred, leading to less energy wasted and a higher and more consistent transport rate over the colony. However, this behaviour is unrecorded and most likely infrequent if it exists at all. It's possible that this could be tested for by giving the ants a steep or vertical gradient with patches of Fluon (a paint which prevents insects from climbing on a surface) so that the ant may experience surprise destabilisation, which might induce this behaviour. This may have to be done with the sliding track method employed by Moll et al in their study (Moll, et al., 2010).

Irregular load shape and therefore, weight distribution makes it difficult to say with any certainty, but the steady decrease in head angle when climbing at declines of greater magnitude would suggest that shifting the weight of the leaf (and therefore, the centre of mass) forward rather than back is increasingly beneficial to the ants as the decline tends towards verticality. To test this hypothesis, pre-cut paper fragments of a variety of shapes could be used, though the best results may be achieved using a dense type of paper and small fragments. If the ants were exposed to a decline which grew steadily steeper and recording at various points along that trail, then it would be possible to observe a change in head angle adaptations.

With this in mind, I suggest that the angle at which the ant carries its head and therefore its load is entirely a choice at lower angles. However, as will be detailed in the subsequent chapter, there is cause to believe that this aspect of their behaviour is altered by necessity in steep or vertical angles.

\subsubsection{Ant size, leaf size and density}

Larger ants tended to cut heavier leaf fragments across all angles tested. This is almost certainly due to larger ants simply having more muscle mass and being able to more easily transport the load, though increased grip may also be a factor. Longer ants may also be able to better counteract the forces exerted by the loads. 
In general, larger ants also cut larger leaf fragments, though exceptions to this were found at $-90^{\circ},-18^{\circ}$ and $36^{\circ}$. In this past, this has been attributed to the ants effectively using their bodies as a measuring stick by clamping onto the leaf and rotating their body in an arc, though the ants have been shown to adjust the arc of their cut in response to density and leaf thickness (Vanbreda and Stradling, 1994), the latter of which was not measured in this study. However, analysing density showed that when carrying loads uphill, there was no evidence to suggest bigger ants cut from denser leaves, while the opposite was true for $0^{\circ}$ and downhill angles (with the notable exception of -18). A small decline of $-18^{\circ}$ also had noticeably lower ant masses than any other angle (see figure 14). Larger ants cut from denser leaves when travelling downhill and made smaller adjustments in general. Denser leaves should cause a larger shift in the centre of mass for the same adjustment and therefore, the same shift in mass can be achieved with a smaller adjustment. By the same mechanism, if the ant needed to regain control, it could do so with a smaller change in the angle of its head which is of particular importance when on steep downhill gradients and the leaf would fall away from the ant, rather than towards it. Therefore, during journeys with a higher risk of losing the load, it should logically benefit the ant to take a denser leaf fragment, which would explain the results found here. To confirm this, an experiment could be performed using paper disks of various densities and then disturbing the trail so their reaction could be observed.

All leaves in this study were taken from the same bush of Lugustrum vulgare and the experiment took place over the course of three months, March to June. Though the leaves were chosen blind, this is a time of year in which the plant produces a lot of fresh growth and as a result, density had the capacity to vary significantly and so did nutritional content. While this does provide supporting evidence, to confirm earlier work would require a more focused experimental design than mine. Again, the standard practice of using paper fragments but of different densities (e.g. 80 gsm and $160 \mathrm{gsm}$ ) could be applied, though as that would also affect weight, it may be advisable to allow the ants to cut their own fragments from a sheet, rather than 
provide fragments of a fixed size. While paper with twice the thickness should logically have twice the nutritional value, it should be identical from an olfactory and visual perspective, meaning the ants should perceive the two as having the same nutritional value. 


\subsection{Limitations and results of other choices}

\subsubsection{Gradient and speed}

Unlike Holt and Askew (2012) who explained regulation of metabolic rate through the modification of speed in unladen ants, this study focuses on laden ants and showed markedly different results. Unlike the U-shaped curve of Holt and Askew's ants, the laden ants in my experiment showed a relatively stable speed when travelling downhill with their loads, but a marked and steady decrease in speed as the uphill gradient became more extreme (see figure 6).

It seems likely that if Atta cephalotes regulates its metabolic rate in the same way as Acromyrmex octispinosus, that they continue to do this, at least on uphill angles. If the benefits of regulating metabolic rate (such as avoiding fatigue) exist while unloaded, they should only increase in importance when laden and energy costs increase. However, Holt and Askew's work suggests that both uphill and downhill angles have similar costs involved and if regulating metabolic rate through the increase and decrease in speed was the only factor, downhill speeds should mirror the uphill speeds.

It has been shown previously that the desert ants of Cataglyphis increase or decrease their speed when their stride length is artificially lengthened using stilts or shortened by amputating part of the leg (Wittlinger, Wehner and Wolf, 2007) and evidence exists to suggest that other leaf cutting ants of Atta columbica also have their movement speed tied to the length of their legs (Burd, 1996). It seems reasonable to suggest that Atta cephalotes would be similar and larger ants would take bigger strides, resulting in a faster movement speed. As previously mentioned, larger ants would generally cut when they had to transport leaves downhill and speed did correlate with ant mass over both uphill and downhill angles. This suggests that the difference in speed across various gradients is in at least in part, due to ants that decide to cut and that the speed is dictated by the stride length of those, rather than the ants deciding to move faster or slower at particular gradients. 
One might expect the angle of the body, which would be induced by extending the legs might have had an effect but there was no significant correlation across the angles tested. This suggests that while the ants do vary the angle at which they hold their body and thus, the extension of their legs, they do this in a way which does not significantly impact their speed, which could only occur if such extensions were small enough that they didn't force a change in the way the ants walk.

\subsubsection{Gradient, transport rate and loading ratio}

Transport rate was calculated with the equation (load mass $\mathrm{x}$ speed) and loading ratio was calculated using the equation ((ant weight + leaf weight)/ant weight). As load mass (leaf weight), speed and ant weight were all significantly affected by gradient, it would be expected that loading ratio and transport rate would both be significantly affected as well. This was indeed the case across all angles, as well as uphill and downhill angles taken in isolation for transport rate, but only downhill gradients significantly impacted loading ratio. In this study, loading ratios were smaller than those reported by Lewis et al (2008).

Loading ratio is a measure of how the ants burden themselves relative to their size and as uphill gradients had no significant effect on the size of the ants which cut or the size of the load that they cut, it is unsurprising that loading ratio wasn't significantly affected by uphill gradients. This could once again be related to modulation through speed in order to keep a consistent metabolic rate, since transport uphill resulted in much slower movement speeds (see figure 6). Both uphill travel and increased load would incur increased metabolic costs but over such a short distance, I doubt fatigue would be a serious factor as the trail used here was a mere $1 / 125^{\text {th }}$ of the length of trails observed in wild colonies (Lewis et al, 1974). It is possible that they simply do this anyway in anticipation of potential disruptions to the route, caused by falling branches, rain washing away part of the trail, branch bridges over obstacles falling away and similar events, though these disruptions would have to be common for it to be worth it. 
As for transport rate, a derivative of load mass and speed and ultimately, the end result which the ants should optimise, gradient did have a significant effect. This effect is unsurprising considering the slow rate of travel for uphill angles. My results concur with those of Lewis et al (2008) and show a more difficult uphill return journey will result in both lower speeds and lower load masses. When travelling downhill, transport rate was highest at a $54^{\circ}$ decline, which is surprising considering that when the ants are descending, it is often down the trunks of trees. However ant trails frequently travel uphill when near to the colony, as a result of their hygiene procedures (Hart and Ratnieks, 2002). In established colonies, external waste dumps are located downhill if possible, to prevent water runoff from contaminating the nest and $92 \%$ of foraging trails orientate themselves away from the nest (Hart and Ratnieks, 2002). While it is entirely possible that these trails may lead over relatively flat ground, many colonies will have little choice but to head uphill if they want to avoid venturing close to the waste dumps and as a result, will have to transport downhill on their return and adaptations to this may have resulted in faster transport rates overall and therefore, a greater yield of fungus and brood. While they do climb trees, this may end up being a small proportion of their journey if they are foraging from bushes or fallen branches, when compared to declines and thus, adapting for faster rates on declines, rather than vertical descents may have been optimal.

\subsubsection{Gradient and compensation through adjustment to the head and body angles}

It seems likely that at less extreme angles, the ants choose to adjust their heads backwards to achieve greater stability. However, at extreme gradients and particularly vertical or near vertical gradients, ants consistently move their heads to angles that shift the weight further forward than at shallower angles which suggests that forcing the centre of mass forward has some advantage. There are two possible explanations for this. The first is that shifting the centre of mass and the leaf mass forward also shifts it closer to the trail and thus, we might expect less leverage on the ant's claws, reducing the amount of force that each claw has to bare, reducing the chance of slippage or breakage. The second is based upon the work done by Endlein and Federle, 
with the weaver ant, Oecophylla smaragdina, which utilises different parts of its tarsus in order to optimise grip when travelling horizontally, vertically and upside down, based on whether that particular leg was above or below the centre of mass (Endlein and Federle, 2015). Micrographs of $A$. cephalotes tarsi taken by Stark et al (2019) reveal hair like structures similar to those described by Endlein and Federle, as well as pointing out that the tarsi of $A$. cephalotes are prehensile, often being used in the manipulation of leaf fragments for cutting and cleaning (Stark et al, 2019). With this in mind, it would not be unreasonable to suggest that $A$. cephalotes utilises different parts of its prehensile tarsi in much the same way as $O$. smaragdina does to optimise its ability to grip when gravitational forces pull on it in different directions. Assuming that like in $O$. smaragdina, that certain ways of gripping to the surface are optimal when the centre of mass in front or behind that particular leg, it may be optimal to shift the centre of mass forward, so that all legs are behind it when travelling downhill, to enable them to utilise the gripping technique with the most grip. It should be noted that all research detailing the strength of these ants suggests that the lowering of the head is not forced by the weight of the leaf, which would make this a decision on the ant's part to deliberately shift the weight forward. However, if this were the case, we might expect more of the ants to have lowered their heads than the $13 \%$ (164/1288) of ants which did so. It is possible that the ants are cautious and rather than shifting their load forward quickly and potentially causing excess leverage forces or a loss of grip, make small adjustments. It is unlikely that this is due to a shared trait inducing this behaviour in this $13 \%$ as they appeared to be a variety of sizes, carry a wide range of leaf masses, move at differing speeds and held their bodies at a wide range of angles.

As for travelling uphill, it seems likely it is a matter of bringing the weight more in line with the back legs. Unlike travelling vertically downhill, where the weight is near a potential pivot (in that case, the front legs which would presumably be the last to lose grip as the ant toppled over forward), when travelling uphill, it is far away from a potential pivot (in that case, the back legs). As a result, the most important factor affecting the ant would be the management of leverage forces which would pull the 
ant away from the surface, like opening a door at the handle, rather than the hinge. By shifting the weight as close to directly in front of the ant as possible, the ants would minimise these leverage forces and place them directly into the direction of travel, which the back legs are pushing against anyway, in order to propel the ant forward.

\subsubsection{Leaf weight and speed}

Ant speeds decreased with leaf weight across all angles, but these were only statistically significant at the more extreme angles, both uphill and downhill. However, in this study, leaf weight was not a limiting factor (ants in this study carried loads much smaller than the $600 \%$ of ant mass reported in other studies (Wetterer, 1994)).

It seems more likely that this decrease was a consequence of ant size, gradient and speed, rather than the size of the leaf being causal. Across most of the gradients tested here larger ants took larger loads and, in many cases, moved slower as a result of needing to maintain a firm grip. With larger ants tending to cut at steeper gradients, ants on steeper gradients tending to move slower and larger ants tending to cut heavier loads, it seems likely that the cause was gradient, rather than the weight of the leaves themselves. This could be confirmed with an experiment involving cut fragments of paper of a uniform size and shape at various gradients.

\subsubsection{Ant size, speed and transport rate}

When carrying along slopes of $-54^{\circ},-18^{\circ}, 0^{\circ}, 18^{\circ}$ and $36^{\circ}$, there was no indication that larger ants moved faster than smaller nestmates but at other angles, larger ants moved significantly faster. A possible explanation for this is that larger ants with longer legs are able to more easily make adjustments and compensate for the different gait which a slope would force. Moving uphill or downhill would require a lengthening of some legs and a shortening of others to keep the body level (see figure 12), possibly to an extent which may be unreachable or difficult for some smaller ants, which would force a reduction in stride length to compensate. A larger ant would need to make smaller or less strenuous adjustments to its gait and be able to maintain a longer stride length and also a stride length closer to its maximum stride length. 
Transport rate almost universally increased with ant size with the only exception being at $36^{\circ}$. Considering that transport rate is calculated using leaf weight (which increased with ant size across all angles) and speed, this is unsurprising.

\subsubsection{Adjustments to maintain stability and their effect on speed}

Unlike other analyses conducted here, there appeared to be no clear pattern in regard to which adjustments correlated with speed, but some inferences can still be drawn. All correlations involving the angle between the head and the body (i.e. the adjustment made at the neck) were negatively correlated with speed, suggesting that the ants slow as this adjustment increases, though it is also worth noting that these were only statistically significant at $-36^{\circ}$ and $+90^{\circ}$. The downhill gradients being significant might be due to the extension of the forward pairs of legs. As the body remains fairly stable compared to the track (See figure 12), the ant must lift its body up on its forelegs in order to keep connected to the ground and the body raised. This has the potential to cause difficulty or strain when the ant leans its head back, which might result in a slower movement speed overall. It is also possible that these gradients take the ant's sensory organs (eyes and antennae) out of range of the trail and they have difficulty perceiving it. With the trail continuing downwards and the ants raising their heads, the distance between the two increases. However, if this were true, we might expect $-72^{\circ}$ to induce the same effect as the adjustments made on $-72^{\circ}$ and $-54^{\circ}$ gradients were similar and so the distance between the head and the track would be similar. Atta have small optic lobes in their brains, which is indicative of poor eyesight, rendering them highly reliant on olfactory cues (Gronenberg and Hölldobler, 1999) and it may be that the angulation was enough that they could not see the trail, which would presumably decrease movement speed, though how much the ants utilise their eyes remains largely unexplored. As for $+90^{\circ}$, tilting the head back further would the leaf further away from the trail and exposing the ant to greater leverage forces, which would likely reduce stride length in order to keep hold of the load by reducing the time in which a particular leg is not gripping. 
Whatever the cause for the cause for the reduction in speed, it is clear that the ants trade off speed for a greater chance of successfully returning the leaf to the nest. Moll et al. (2010) showed convincingly that other Atta species use these head adjustments to maintain stability and thus, more reliably deliver the leaf fragment back to the nest. This study demonstrates the same kind of adjustments, which induce a significant decrease in speed. The overall conclusion is that leaf cutting ants prioritise success over speed and this likely the reason for the common observation that they appear to forage sub-optimally (Burd and Howard, 2005).

The ants could increase their individual transport rate by either increasing the load size or increasing the speed at which they travel but when exposed to a gradient, both carry increased risk. The requirement to grip at steep gradients is counterproductive to moving quickly as not getting a secure enough grip before taking the next step can easily cause the ant to fall. In this case, they would most likely lose the leaf and potentially, lose the trail and be unable to return to the colony which would mean the colony would not only lose the leaf material but have fewer workers able to forage the next day. Large loads make gripping harder, due to not only the increased physical strain which comes with supporting an increased mass, but also by making it harder for the ant to maintain its centre of mass in a desirable location and therefore, making it easier to lose its grip.

Ultimately, a successful trip will benefit the colony more than an unsuccessful one, even if that successful trip took longer and resulted in a lower yield of leaf material. When moving over high-risk terrain (e.g. vertical or steep gradients), it benefits the colony more to ensure that the leaves get through, even if that means slowing down or taking smaller leaves, as a lost leaf fragment is a net loss (as the worker expended energy to get to the foraging site and spent time which could be spent on other tasks) and the loss of a worker would be an even greater loss. 


\subsection{Conclusions}

Throughout this study, two conclusions became abundantly clear. The first is that the ant's first priority is to get the leaf fragment safely back to the nest, with all other considerations (such as speed) being secondary. Secondly, it has become apparent that shallow declines (in this study, $-18^{\circ}$ ) induce markedly different adaptations and behaviours than their equivalent inclines, flat gradients $\left(0^{\circ}\right)$ or steeper gradients.

Ultimately, it seems that grip is the primary factor in ant decision making in regard to gradient, which suggests that the priority is actually getting the leaf back to the nest. While leaf fragments which are transported more slowly may result in more energy being expended and therefore, a smaller gain to the colony, it is at least some gain. If the leaf is lost, or worse still, both leaf and worker are lost, it represents a net loss to the colony in terms of energy, as well as a reduction in the operational capacity of the colony as a whole. While previous experiments by Moll et al (2010) showed attempts to maintain a central centre of mass in grass cutting ants and could reasonably be expected here with the leaf cutting ants, I found that at the extreme angles, the ants appear to deliberately decentralise their centre of mass in order to better facilitate continued grip to the surface. When travelling vertically upwards, this was in an effort to maintain balance and avoid leverage forces induced by the position of the load.

When moving vertically downwards, balance was less of a concern because the load was located close to where a falling ant would pivot and flip over (the front legs) but should allow them to use a method of gripping that produced a stronger gripping force, as seen in Oecophylla smaragdina (Endlein and Federle, 2015). This footage gathered during this study was unfortunately insufficient to confirm this hypothesis, but a relatively simple experiment could be performed to confirm it. Micrographs of the ant's feet could be taken to confirm they have the same structures as $O$.

smaragdina and finally, high resolution footage of the ant's feet as they move along trails at various angles to confirm if the same behaviour that Endlein and Federle (2015) described is present in Atta. Regardless of the outcome of such an experiment, every aspect of the data gathered in this study seems to suggest that grip and the 
successful delivery of leaf fragments to the nest is more important than the size of the fragments or the speed at which they are delivered. Even a small chance of losing the leaf and the load when multiplied over the vast swarms of hundreds of thousands of ants that $A$. cephalotes musters would result in a huge loss of energy for the colony, though this may be somewhat mitigated by many lost workers having a greater likelihood of finding the trail again through random searching, assuming they weren't predated first. It should also be noted that the loss of a worker affects not only that days foraging but also means that there are fewer workers to forage tomorrow and fewer workers to defend against threats such as Nomamyrmex esenbeckii swarms which predate mature A. cephalotes colonies (Swartz, 1998).

The ants seemed to move fastest and have the highest rates of leaf transport on either flat or downhill gradients. This result suggests that $A$. cephalotes is more commonly faced with transporting leaves downhill and colonies which were better able to do that would have outcompeted neighbouring colonies. This can at least be partially explained by the obvious fact that ants who climb a tree to cut leaf fragments, must then transport it down the trunk again and any vertically uphill sections along the trail should be smaller. As Hart and Ratnieks (2001) pointed out, their waste dumps are usually located downhill from the nest where possible and the vast majority of foraging trails move away from these waste dumps. With the exception of nests that were located on the top of a mound or hill (a relatively unlikely occurrence), the foraging workers would move either uphill or on an approximately flat angle when leaving the nest, meaning that they would have to carry the leaf fragments downhill to return it to the nest. However, this is supposition based on trail orientation and a survey of foraging trails in wild colonies would have be conducted to confirm this hypothesis.

The same large ants which carried leaf fragments when the trail was more difficult also moved at a faster speed than smaller nestmates. I believe this to be a consequence of the necessity for greater grip and the ants with greater gripping strength being larger. Larger individuals have longer legs, enabling a greater distance to be covered with each stride, though it is also possible that the speed at which a larger worker could 
carry is a consideration undertaken at the foraging site. However, it is likely to be secondary to the consideration of grip and the likelihood of a successful delivery back to the nest. The fact that smaller workers don't cut when faced with a steep gradient suggests that they're able to not only consider their own capabilities but also those of their nest mates, as without this knowledge, they would be expected to cut smaller fragments. With the knowledge that larger nest mates can do the job more efficiently, they can safely leave the task to their nest mates.

It should be noted that during this experiment, there were no noticed examples of an ant which cut, but then did not carry the leaf back to the nest, as has been reported in the wild (Roschard and Roces, 2003). This could be due to the short distance from the nest, a laboratory artefact induced by the different conditions faced by the ants in the laboratory or it could be explained through some mechanism surrounding the behaviour that remains unexplained. To investigate if this would have made a difference, this experiment would have to be repeated in a wild colony, potentially by exploiting their natural tendency to incorporate smooth logs as part of their trails in the wild (Farji-Brener et al., 2007).

With the discovery of their prioritisation of grip, rather than balance or speed as has been previously suggested on normal trails (Farji-Brener et al., 2011, Moll et al, 2010), it raises implications that affect many previous studies and a new lens with which to look at leaf cutting ant foraging that has previously been underappreciated. This also serves as at least part of explanation behind the sub-optimal foraging in Atta. By placing a greater emphasis on ensuring no effort is wasted, they reduce their colony wide transport rate but avoid wasting their investment in individual workers and the energy put into those workers. More cautious, sub-optimal foraging could result in a higher return of plant material to the nest than optimal, but riskier foraging and thus be evolutionarily beneficial. 


\section{References}

Arkes, H.R. and Ayton, P., 1999. The sunk cost and Concorde effects: Are humans less rational than lower animals?. Psychological bulletin, 125(5), p.591

Arnold, A.E. and Lutzoni, F., 2007. Diversity and host range of foliar fungal endophytes: are tropical leaves biodiversity hotspots?. Ecology, 88(3), pp.541-549.

Augustin, J.O., Simões, T.G., Dijksterhuis, J., Elliot, S.L. and Evans, H.C., 2017. Putting the waste out: a proposed mechanism for transmission of the mycoparasite Escovopsis between leafcutter ant colonies. Royal Society open science, 4(5), p.161013.

Basey, J.M., Jenkins, S.H. and Busher, P.E., 1988. Optimal central-place foraging by beavers: tree-size selection in relation to defensive chemicals of quaking aspen. Oecologia, 76(2), pp.278-282.

Bass, M. and Cherrett, J.M., 1995. Fungal hyphae as a source of nutrients for the leafcutting ant Atta sexdens. Physiological Entomology, 20(1), pp.1-6.

Batra, S.W., 1968. Behavior of some social and solitary halictine bees within their nests: a comparative study (Hymenoptera: Halictidae). Journal of the Kansas Entomological Society, pp.120-133.

Bernadou, A., Espadaler, X., Dos-Reis, V. and Fourcassié, V., 2011. Effect of substrate roughness on load selection in the seed-harvester ant Messor barbarus L.(Hymenoptera, Formicidae). Behavioral Ecology and Sociobiology, 65(9), p.1763.

Bochynek, T., Meyer, B. and Burd, M., 2017. Energetics of trail clearing in the leafcutter ant Atta. Behavioral ecology and sociobiology, 71(1), p.14. 
Bordereau, C., Robert, A., Van Tuyen, V. and Peppuy, A., 1997. Suicidal defensive behaviour by frontal gland dehiscence in Globitermes sulphureus Haviland soldiers (Isoptera). Insectes Sociaux, 44(3), pp.289-297.

Burd, M., 1995. Variable load size-ant size matching in leaf-cutting ants, Atta colombica (Hymenoptera: Formicidae). Journal of insect behavior, 8(5), pp.715-722.

Burd, M., 1996. Foraging performance by Atta colombica, a leaf-cutting ant. The American Naturalist, 148(4), pp.597-612.

Burd, M., 2000. Foraging behaviour of Atta cephalotes (leaf-cutting ants): an examination of two predictions for load selection. Animal behaviour, 60(6), pp.781788.

Burd, M. and Howard, J.J., 2005. Central-place foraging continues beyond the nest entrance: the underground performance of leaf-cutting ants. Animal Behaviour, 70(4), pp.737-744.

Chittka, A., Wurm, Y. and Chittka, L., 2012. Epigenetics: the making of ant castes. Current Biology, 22(19), pp.R835-R838.

Currie, C.R., Poulsen, M., Mendenhall, J., Boomsma, J.J. and Billen, J., 2006. Coevolved crypts and exocrine glands support mutualistic bacteria in fungus-growing ants. Science, 311(5757), pp.81-83.

Currie, C.R. and Stuart, A.E., 2001. Weeding and grooming of pathogens in agriculture by ants. Proceedings of the Royal Society of London. Series B: Biological Sciences, 268(1471), pp.1033-1039. 
Czaczkes, T.J., Grüter, C. and Ratnieks, F.L., 2013. Negative feedback in ants: crowding results in less trail pheromone deposition. Journal of the Royal Society Interface, 10(81), p.20121009.

Dellatore, D.F., Waitt, C.D. and Foitova, I., 2009. Two cases of mother-infant cannibalism in orangutans. Primates, 50(3), pp.277-281.

Dijkstra, M.B. and Boomsma, J.J., 2006. Are workers of Atta leafcutter ants capable of reproduction?. Insectes Sociaux, 53(2), pp.136-140.

Dussutour, A., Beshers, S., Deneubourg, J.L. and Fourcassie, V., 2007. Crowding increases foraging efficiency in the leaf-cutting ant Atta colombica. Insectes sociaux, 54(2), pp.158-165.

Endlein, T. and Federle, W., 2015. On heels and toes: how ants climb with adhesive pads and tarsal friction hair arrays. PloS one, 10(11), p.e0141269.

Estrada, C., Wcislo, W.T. and Van Bael, S.A., 2013. Symbiotic fungi alter plant chemistry that discourages leaf-cutting ants. New Phytologist, 198(1), pp.241-251.

Evison, S.E. and Ratnieks, F.L., 2007. New role for majors in Atta leafcutter ants. Ecological Entomology, 32(5), pp.451-454.

Falcão, P.F., Pinto, S.R.R., Wirth, R. and Leal, I.R., 2011. Edge-induced narrowing of dietary diversity in leaf-cutting ants. Bulletin of entomological research, 101(3), pp.305311.

Farji-Brener, A.G., Barrantes, G., Laverde, O., Fierro-Calderón, K., Bascopé, F. and López, A., 2007. Fallen branches as part of leaf-cutting ant trails: Their role in resource discovery and leaf transport rates in Atta cephalotes. Biotropica, 39(2), pp.211-215. 
FARJI-BRENER, A.G., Chinchilla, F.A., Rifkin, S., SÁNCHEZ CUERVO, A.M., Triana, E., Quiroga, V. and Giraldo, P., 2011. The 'truck-driver'effect in leaf-cutting ants: how individual load influences the walking speed of nest-mates. Physiological entomology, 36(2), pp.128-134.

Fernández-Marín, H., Zimmerman, J.K., Rehner, S.A. and Wcislo, W.T., 2006. Active use of the metapleural glands by ants in controlling fungal infection. Proceedings of the Royal Society B: Biological Sciences, 273(1594), pp.1689-1695.

Franks, N.R. and Richardson, T., 2006. Teaching in tandem-running ants. Nature, 439(7073), p.153.

Full, R.J. and Tullis, A.L.E.X.A., 1990. Energetics of ascent: insects on inclines. Journal of Experimental Biology, 149(1), pp.307-317.

Goulart, V.D. and Young, R.J., 2013. Selfish behaviour as an antipredator response in schooling fish?. Animal behaviour, 86(2), pp.443-450.

Griffiths, H.M. and Hughes, W.O., 2010. Hitchhiking and the removal of microbial contaminants by the leaf-cutting ant Atta colombica. Ecological Entomology, 35(4), pp.529-537.

Gronenberg, W. and Hölldobler, B., 1999. Morphologic representation of visual and antennal information in the ant brain. Journal of Comparative Neurology, 412(2), pp.229-240.

Farji-Brener, A.G., Chinchilla, F., Umaña, M.N., Ocasio-Torres, M.E., Chauta-Mellizo, A., Acosta-Rojas, D., Marinaro, S., de Torres Curth, M. and Amador-Vargas, S., 2015. Branching angles reflect a trade-off between reducing trail maintenance costs or travel distances in leaf-cutting ants. Ecology, 96(2), pp.510-517. 
Haeder, S., Wirth, R., Herz, H. and Spiteller, D., 2009. Candicidin-producing Streptomyces support leaf-cutting ants to protect their fungus garden against the pathogenic fungus Escovopsis. Proceedings of the National Academy of Sciences, 106(12), pp.4742-4746.

Hart, A.G. and Ratnieks, F.L., 2001. Task partitioning, division of labour and nest compartmentalisation collectively isolate hazardous waste in the leafcutting ant Atta cephalotes. Behavioral Ecology and Sociobiology, 49(5), pp.387-392.

Hart, A.G. and Ratnieks, F.L., 2001. Leaf caching in the leafcutting ant Atta colombica: organizational shift, task partitioning and making the best of a bad job. Animal Behaviour, 62(2), pp.227-234.

Hart, A.G. and Ratnieks, F.L., 2002. Waste management in the leaf-cutting ant Atta colombica. Behavioral Ecology, 13(2), pp.224-231.

Hölldobler, B. and Wilson, E.O., 1990. The ants. Harvard University Press.

Hölldobler, B. and Wilson, E.O., 1977. The number of queens: an important trait in ant evolution. Naturwissenschaften, 64(1), pp.8-15.

Holt, N.C. and Askew, G.N., 2012. Locomotion on a slope in leaf-cutter ants: metabolic energy use, behavioural adaptations and the implications for route selection on hilly terrain. Journal of Experimental Biology, 215(15), pp.2545-2550.

Howard, J.J., 2001. Costs of trail construction and maintenance in the leaf-cutting ant Atta columbica. Behavioral Ecology and Sociobiology, 49(5), pp.348-356. 
Hubbell, S.P., Johnson, L.K., Stanislav, E., Wilson, B. and Fowler, H., 1980. Foraging by bucket-brigade in leaf-cutter ants. Biotropica, pp.210-213.

Jaffe, K. and Howse, P.E., 1979. The mass recruitment system of the leaf cutting ant, Atta cephalotes (L.). Animal Behaviour, 27, pp.930-939.

Jaffe, K., 2008. Leaf-Cutting Ants (Formicidae: Myrmicinae: Attini). Encyclopedia of Entomology, pp.2151-2158.

Jones, T.H., Clark, D.A., Edwards, A.A., Davidson, D.W., Spande, T.F. and Snelling, R.R., 2004. The chemistry of exploding ants, Camponotus spp.(cylindricus complex). Journal of chemical ecology, 30(8), pp.1479-1492.

Klok, C, 2011. Heavy loads, slow truck drivers and ants. Journal of Experimental Biology, 214(13), pp 6.

Kost, C., Tremmel, M. and Wirth, R., 2011. Do leaf cutting ants cut undetected? Testing the effect of ant-induced plant defences on foraging decisions in Atta colombica. PLoS One, 6(7), p.e22340.

Lanan, M., 2014. Spatiotemporal resource distribution and foraging strategies of ants (Hymenoptera: Formicidae). Myrmecological news/Osterreichische Gesellschaft fur Entomofaunistik, 20, p.53.

Leal, I.R., Wirth, R. and Tabarelli, M., 2014. The multiple impacts of leaf-cutting ants and their novel ecological role in human-modified neotropical forests. Biotropica, 46(5), pp.516-528. 
Lewis, O.T., Martin, M. and Czaczkes, T.J., 2008. Effects of trail gradient on leaf tissue transport and load size selection in leaf-cutter ants. Behavioral Ecology, 19(4), pp.805809.

Lewis, T., Pollard, G.V. and Dibley, G.C., 1974. Rhythmic foraging in the leaf-cutting ant Atta cephalotes (L.)(Formicidae: Attini). The Journal of Animal Ecology, pp.129-141.

Lipp, A., Wolf, H. and Lehmann, F.O., 2005. Walking on inclines: energetics of locomotion in the ant Camponotus. Journal of Experimental Biology, 208(4), pp.707719.

Little, A.E., Murakami, T., Mueller, U.G. and Currie, C.R., 2003. The infrabuccal pellet piles of fungus-growing ants. Naturwissenschaften, 90(12), pp.558-562.

Lopes, Pedro. (2013). Metric relations between body parts in Atta sexdens rubropilosa. XXI Simpósio Internacional de Mirmecologia, Fortaleza, Brazil, 1-5 December.

Loreto, R.G., Hart, A.G., Pereira, T.M., Freitas, M.L., Hughes, D.P. and Elliot, S.L., 2013. Foraging ants trade off further for faster: use of natural bridges and trunk trail permanency in carpenter ants. Naturwissenschaften, 100(10), pp.957-963.

Mundim, F.M., Bruna, E.M., Vieira-Neto, E.H. and Vasconcelos, H.L., 2012. Attack frequency and the tolerance to herbivory of Neotropical savanna trees. Oecologia, 168(2), pp.405-414.

Nichols-Orians, C.M. and Schultz, J.C., 1989. Leaf toughness affects leaf harvesting by the leaf cutter ant, Atta cephalotes (L.)(Hymenoptera: Formicidae). Biotropica, pp.8083. 
Norton, V., Stevens-Wood, B. and Harris, W.E., 2014. Flexibility of individual load-mass selection in relation to foraging trail gradient in the leaf-cutter ant Acromyrmex octospinosus. Journal of insect behavior, 27(3), pp.370-384.

Packer, C., Pusey, A.E. and Eberly, L.E., 2001. Egalitarianism in female African lions. Science, 293(5530), pp.690-693.

Pattrick, J.G., Labonte, D. and Federle, W., 2018. Scaling of claw sharpness: Mechanical constraints reduce attachment performance in larger insects. Journal of Experimental Biology, 221(24), p.jeb188391.

Peeters, C., 2012. Convergent evolution of wingless reproductives across all subfamilies of ants, and sporadic loss of winged queens (Hymenoptera: Formicidae). Myrmecological News, 16, pp.75-91.

Planqué, R., Van Den Berg, J.B. and Franks, N.R., 2010. Recruitment strategies and colony size in ants. PLoS One, 5(8), p.e11664.

Ribeiro Neto, J.D., Pinho, B.X., Meyer, S.T., Wirth, R. and Leal, I.R., 2012. Drought stress drives intraspecific choice of food plants by A tta leaf-cutting ants. Entomologia Experimentalis et Applicata, 144(2), pp.209-215.

Römer, D. and Roces, F., 2014. Nest enlargement in leaf-cutting ants: relocated brood and fungus trigger the excavation of new chambers. PLoS One, 9(5), p.e97872.

Röschard, J. and Roces, F., 2003. Cutters, carriers and transport chains: distancedependent foraging strategies in the grass-cutting ant Atta vollenweideri. Insectes Sociaux, 50(3), pp.237-244. 
Rudolph, S.G. and Loudon, C., 1986. Load size selection by foraging leaf-cutter ants (Atta cephalotes). Selección del tamaño de la carga por parte de hormigas zompopas forrajeras (Atta cephalotes). Ecological Entomology., 11(4), pp.401-410. Saverschek, N., Herz, H., Wagner, M. and Roces, F., 2010. Avoiding plants unsuitable for the symbiotic fungus: learning and long-term memory in leaf-cutting ants. Animal Behaviour, 79(3), pp.689-698.

Schofield, R.M., Emmett, K.D., Niedbala, J.C. and Nesson, M.H., 2011. Leaf-cutter ants with worn mandibles cut half as fast, spend twice the energy, and tend to carry instead of cut. Behavioral Ecology and Sociobiology, 65(5), pp.969-982.

Shepherd, J.D., 1982. Trunk trails and the searching strategy of a leaf-cutter ant, Atta colombica. Behavioral Ecology and Sociobiology, 11(2), pp.77-84.

Shutler, D. and Mullie, A., 1991. Size-related foraging behaviour of the leaf-cutting ant Atta colombica. Canadian journal of zoology, 69(6), pp.1530-1533.

Stark, A.Y., Davis, H.R. and Harrison, W.K., 2019. Shear adhesive performance of leafcutting ant workers (Atta cephalotes). Biotropica, 51(4), pp.572-580.

Suen, G., Teiling, C., Li, L., Holt, C., Abouheif, E., Bornberg-Bauer, E., Bouffard, P., Caldera, E.J., Cash, E., Cavanaugh, A. and Denas, O., 2011. The genome sequence of the leaf-cutter ant Atta cephalotes reveals insights into its obligate symbiotic lifestyle. PLoS Genetics, 7(2), p.e1002007.

Swartz, M.B., 1998. Predation on an Atta cephalotes colony by an army ant Nomamyrmex esenbecki. Biotropica, 30(4), pp.682-684.

Ting, L.H., Blickhan, R. and Full, R.J., 1994. Dynamic and static stability in hexapedal runners. Journal of Experimental Biology, 197(1), pp.251-269. 
Tschinkel, W.R. and Kwapich, C.L., 2016. The Florida harvester ant, Pogonomyrmex badius, relies on germination to consume large seeds. PloS one, 11(11), p.e0166907.

Van Bael, S.A., Seid, M.A. and Wcislo, W.T., 2012. Endophytic fungi increase the processing rate of leaves by leaf-cutting ants (Atta). Ecological Entomology, 37(4), pp.318-321.

Van Breda, J.M. and Stradling, D.J., 1994. Mechanisms affecting load size determination inAtta cephalotes L.(Hymenoptera, Formicidae). Insectes Sociaux, 41(4), pp.423-435.

Vieira-Neto, E.H.M., Mundim, F.M. and Vasconcelos, H.L., 2006. Hitchhiking behaviour in leaf-cutter ants: an experimental evaluation of three hypotheses. Insectes sociaux, 53(3), pp.326-332.

Wager, B.R. and Breed, M.D., 2000. Does honey bee sting alarm pheromone give orientation information to defensive bees?. Annals of the Entomological Society of America, 93(6), pp.1329-1332.

Wetterer, J.K., 1994. Forager polymorphism, size-matching, and load delivery in the leaf-cutting ant, Atta cephalotes. Ecological Entomology, 19(1), pp.57-64.

Wetterer, J.K., 1991. Source distance has no effect on load size in the leaf-cutting ant, Atta cephalotes. Psyche: A Journal of Entomology, 98(4), pp.355-359.

Wheeler, W.M., 1911. The ant-colony as an organism. Journal of Morphology, 22(2), pp.307-325. 
Wirth, Rainer \& Herz, Hubert \& Ryel, Ronald \& Beyschlag, Wolfram \& Hölldobler, Bert. (2003). Herbivory of Leaf-Cutting Ants: A Case Study on Atta Colombica in the Tropical Rainforest of Panama. 10.1007/978-3-662-05259-4.

Wittlinger, M., Wehner, R. and Wolf, H., 2007. The desert ant odometer: a stride integrator that accounts for stride length and walking speed. Journal of experimental Biology, 210(2), pp.198-207.

Wojtusiak, J., Godzińska, E.J. and Dejean, A., 1995. Capture and retrieval of very large prey by workers of the African weaver ant, Oecophylla longinoda (Latreille 1802). Tropical Zoology, 8(2), pp.309-318.

Worsley, S.F., Innocent, T.M., Heine, D., Murrell, J.C., Douglas, W.Y., Wilkinson, B., Hutchings, M.I., Boomsma, J.J. and Holmes, N.A., 2018. Symbiotic partnerships and their chemical interactions in the leafcutter ants (Hymenoptera: Formicidae). Myrmecological News, 27, pp.59-74.

Zollikofer, C., 1994. Stepping patterns in ants-influence of load. Journal of experimental biology, 192(1), pp.119-127. 